Check for updates

Cite this: RSC Adv., 2019, 9, 14782

Received 5th March 2019

DOI: 10.1039/c9ra01672d

rsc.li/rsc-advances Accepted 17th April 2019

\section{Adsorption and anticorrosive behavior of aromatic epoxy monomers on carbon steel corrosion in acidic solution: computational studies and sustained experimental studies $\uparrow$}

\author{
Omar Dagdag, (iD a Zaki Safi, (DD ${ }^{\mathrm{b}}$ Hamid Erramli, ${ }^{\mathrm{c}}$ Omar Cherkaoui, ${ }^{\mathrm{d}}$ Nuha Wazzan, ${ }^{\mathrm{e}}$ \\ Lei Guo, (D) ${ }^{f}$ Chandrabhan Verma, (D)*gh E. E. Ebenso (D)*gh and Ahmed El Harfi ${ }^{a}$
}

\begin{abstract}
Herein, the synthesis, characterization and corrosion inhibition effectiveness of two aromatic epoxy monomers (AEMs) namely, 2-(oxiran-2-yl-methoxy)-N,N-bis(oxiran-2-yl-methyl)aniline (AEM1) and N,Nbis(oxiran-2-ylmethyl)-2-((oxiran-2-ylmethyl) thio)aniline (AEM2), in carbon steel corrosive dissolution in $1 \mathrm{M} \mathrm{HCl}$ solution is investigated using computational and experimental techniques. AEM1 and AEM2 were characterized using FT-IR, ${ }^{1} \mathrm{H} N \mathrm{NMR}$ and ${ }^{13} \mathrm{C}$ NMR spectroscopy techniques. Electrochemical results demonstrated that AEMs act as reasonably good corrosion inhibitors for carbon steel in $1 \mathrm{M} \mathrm{HCl}$ medium and their effectiveness followed the sequence: AEM2 (95.4\%) > AEM1 (94.3\%). A PDP study showed that AEMs act as mixed-type inhibitors with slight anodic predominance. Adsorption of the AEMs obeyed the Langmuir isotherm model. Interactions between AEMs and the metallic surface was further studied using DFT and MD simulations that give several computational parameters such as $I, A, E_{\mathrm{HOMO}}, E_{\mathrm{LU}}, \Delta E, \delta, \chi$, $\rho, \sigma, \eta, \Delta N$ and $E_{\text {ads. }}$. The experimental and computational results were in good agreement and well complimented each other.
\end{abstract}

\section{Introduction}

Carbon and mild steel alloys have great importance in a variety of industrial applications because of their excellent mechanical properties and low cost. However, they are highly unstable in aggressive environments mostly during acidic cleaning processes. ${ }^{1-5}$ A review of the literature shows that the presence

${ }^{a}$ Laboratory of Agroresources, Polymers and Process Engineering (LAPPE), Department of Chemistry, Faculty of Science, Ibn Tofail University, BP 133, 14000 Kenitra, Morocco ${ }^{b}$ Al Azhar University-Gaza, Chemistry Department, Faculty of Science, PO Box 1277, Gaza, Palestine

'Laboratory of Materials, Electrochemistry and Environment, Department of Chemistry, Faculty of Sciences, Ibn Tofail University, Kenitra, Morocco

${ }^{d}$ Higher School of Textile and Clothing Industries, Laboratory REMTEX, BP 7731, Oulfa, Casablanca, Morocco

${ }^{e}$ King Abdulaziz University, Chemistry Department, Faculty of Science, PO Box 42805, Jeddah, 21589, Saudi Arabia

${ }^{f}$ School of Materials and Chemical Engineering, Tongren University, Tongren, 554300, China

${ }^{g}$ Material Science Innovation \& Modelling (MaSIM) Research Focus Area, Faculty of Natural and Agricultural Sciences, North-West University, Private Bag X2046, Mmabatho 2735, South Africa. E-mail: chandraverma.rs.apc@itbhu.ac.in; Eno. Ebenso@nwu.ac.za

${ }^{h}$ Department of Chemistry, Faculty of Natural and Agricultural Sciences, School of Chemical and Physical Sciences, North-West University, Private Bag X2046, Mmabatho 2735, South Africa

$\dagger$ Electronic supplementary information (ESI) available. See DOI: $10.1039 / \mathrm{c} 9 \mathrm{ra} 01672 \mathrm{~d}$ of organic compounds having heteroatoms (such as P, S, O and $\mathrm{N})$ and homo- and hetero-atomic multiple bonds such as $-\mathrm{C} \equiv \mathrm{N},>\mathrm{C}=\mathrm{C}_{-}^{\prime},-\mathrm{N}=\mathrm{O},-\mathrm{N}=\mathrm{N}-,>\mathrm{C}=\mathrm{S},-\mathrm{C}=\mathrm{O},-\mathrm{C}=\mathrm{N}$ etc. minimize the probability and rate of corrosive dissolution. The non-bonding and $\pi$-electrons of heteroatoms and multiple bonds offer co-ordination bonding with d-orbitals of the metals thereby they adsorb and form protective hydrophobic films. ${ }^{6-10}$ Epoxy monomers are widely used in several industrial domains such as high performance adhesives, coatings, construction, architecture, automotive and aeronautical due to their good adhesion ability to the metal surfaces, excellent chemical resistance and good durability. ${ }^{\mathbf{1 1 , 1 2}}$ Epoxy monomers are well established oxygen containing three membered heterocyclic compounds. ${ }^{\mathbf{1 3}, 14}$ Recently, use of corrosion inhibitors based on some aromatic epoxy monomers (AEMs) has gained particular importance because of their relatively high protectiveness, the facile route of synthesis and high purity. ${ }^{\mathbf{1 5 , 1 6}}$ We herein, synthesized two aromatic epoxy monomers (AEMs) as trifunctional molecules designated as AEM1 and AEM2 and tested their anticorrosive properties on the corrosion of carbon steel in $1 \mathrm{M} \mathrm{HCl}$ media. Novelty, of the study is lying behind the facts that these AEMs have never be tested as corrosion inhibitors for steel alloys and they offer reasonably high inhibition efficiency at relatively low concentration. Obviously, AEMs are associated with extensive conjugation in the form of heteroatoms $(\mathrm{N}, \mathrm{S}$, and $\mathrm{O}$ ) and $\pi$-electrons by way of which they can 
adsorb effectually and obstruct corrosion thereafter. Both the tested AEMs have similar molecular structure and they differ from each other with respect to the nature of heteroatoms. Therefore, present study is mainly focused and designed to demonstrate the effect of heteroatoms and their electronegativity on the corrosion inhibition of carbon steel in acidic medium. Both inhibitors were synthesized using commercially available cheap and non-toxic chemicals and solvent (isopropyl alcohol/water) in high yield. The inhibition effect of AEMs was studied using experimental and computational methods using PDP, EIS, DFT and MD methods. Computational and experimental outcomes showed that inhibitor containing relatively less electronegative sulfur atom (AEM2) acts as superior corrosion inhibitor as compared to the inhibitor having more electronegative oxygen atom (AEM1). The results derived from various techniques were in good agreement.

\section{Experimental}

\subsection{Materials}

Carbon steel employed in our previous reports has been used in the present study. ${ }^{\mathbf{1 4 , 1 6}}$ Test solution $(1 \mathrm{M} \mathrm{HCl})$ was prepared by dilution of $37 \%$ analytical grade $\mathrm{HCl}$. The aromatic epoxy monomers were synthesized by the practice described in the literature. ${ }^{17-20}$ Schematic diagram for the preparation of the aromatic epoxy monomers (AEMs) is shown in Fig. 1. In brief, a mixture of an aromatic epoxy monomers compound $\left(10^{-2}\right.$ $\mathrm{mol})$ and ethanol $(10 \mathrm{~mL})$ was added in condenser fitted twonecked RB flask. In the above solution, $2.5 \mathrm{~mL}$ of epichlorohydrin was added at once. After stirring the resulting mixture at $70{ }^{\circ} \mathrm{C}$ for $4 \mathrm{~h}$, mixture was allowed to cool down to $40{ }^{\circ} \mathrm{C}$. After that, $3 \mathrm{~mL}$ of $\mathrm{NEt}_{3}$ was added in the mixture and stirred again for $3 \mathrm{~h}$. The excess epichlorohydrin and the residual solvent were removed using a rotary evaporator in order to obtain the desired viscose solution of resin.

Both aromatic epoxy monomers were characterized using ${ }^{1} \mathrm{H}$ NMR, ${ }^{13} \mathrm{C}$ NMR and FT-IR spectroscopic characterization techniques is shown in Fig. SI 1 and SI $2 . \dagger$ AEM1: yield $92 \%,{ }^{1} \mathrm{H}-$ NMR (DMSO-d $\left.{ }_{6}, 300 \mathrm{MHz}\right): \delta \mathrm{ppm}=2.72,38-2,63(\mathrm{dd}, 8 \mathrm{H}$, $\mathrm{CH}_{2}$ epoxy cycle) (A,B), 2, 77 (m, 2H, CH epoxy cycle) (X), 2.81 (m,

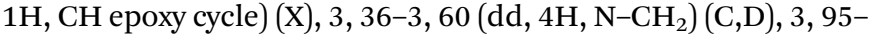
4, 20 (dd, 2H, O- $\mathrm{CH}_{2}$ ) (C,D), 6, 65-6, 92 (s, 4H aromatic ring) (Ar); ${ }^{13} \mathrm{C}-\mathrm{NMR}: \delta \mathrm{ppm}=44,2-45,6\left(\mathrm{~s}, \mathrm{CH}_{2}\right.$ epoxy cycle) (A), 51, 1-51, 9 (s, CH epoxy cycle) (X), $62\left(\mathrm{~s}, \mathrm{~N}-\mathrm{CH}_{2}\right)(\mathrm{C}), 69,4\left(\mathrm{~s}, \mathrm{O}-\mathrm{CH}_{2}\right)$ (C), 113-122 (s, CH aromatic) (Ar), 138, 7; 145, 1 (s, C-C aromatic) (Ar); FTIR-ATR $\left(\mathrm{cm}^{-1}\right): 3257(\mathrm{O}-\mathrm{H}$ and secondary $\mathrm{N}-$ $\mathrm{H}$ ), 2967, 2925, 2877 (C-H vibration), 1600, 1500, 1450 (C=C aromatic), 1295, 1370 (C-N vibration), 1240, 1216, 1089 (C-O), 920, 835 (epoxy groups). AEM2: yield 88\%, ${ }^{1} \mathrm{H}-\mathrm{NMR}$ (DMSO-d ${ }_{6}$, $300 \mathrm{MHz}): \delta \mathrm{ppm}=2,38-2,63\left(\mathrm{dd}, 8 \mathrm{H}, \mathrm{CH}_{2}\right.$ epoxy cycle) (A,B), 2 , 77 (m, 2H, CH epoxy cycle) (X), 3, 04 (m, 1H, CH epoxy cycle) (X), 3, 36-3, 61 (dd, 4H, N-CH $)$ (C,D), 2, 77-3, 02 (dd, 2H, O- $\mathrm{CH}_{2}$ ) (C,D), 6.65-7, 21 (s, 4H aromatic ring) (Ar); ${ }^{13} \mathrm{C}-\mathrm{NMR}: \delta \mathrm{ppm}=$ $45,6-46,8$ (s, $\mathrm{CH}_{2}$ epoxy cycle) (A), 51, 1-53, 4 (s, $\mathrm{CH}$ epoxy cycle) $(\mathrm{X}), 61,3\left(\mathrm{~s}, \mathrm{~N}-\mathrm{CH}_{2}\right)(\mathrm{C}), 40,8\left(\mathrm{~s}, \mathrm{~S}-\mathrm{CH}_{2}\right)(\mathrm{C}), 115-134,6(\mathrm{~s}, \mathrm{CH}$ aromatic) (Ar), 117, 9; 135 (s, C-C aromatic) (Ar); FTIR-ATR $\left(\mathrm{cm}^{-1}\right): 3257$ (NH/OH residual), 2450 (S-H residual), 2967, 2925, 2877 (C-H vibration), 1600, 1500, 1450 ( $\mathrm{C}=\mathrm{C}$ aromatic), 1000-1400 (C-N, C-O, C-S vibration), 950, 835 (epoxy groups)).

\subsection{Electrochemical measurements}

Before performing the experiments, the steel specimens were polished with grit sand papers using different grades (180 to 1000), rinsed with alcohol and distilled water. Stock solution of the inhibitors (AEM1 and AEM2) was prepared by dissolving them in small amount (nearly $2 \mathrm{~mL}$ ) of isopropyl alcohol followed by the addition of tested electrolyte. The electrochemical behavior of an aromatic epoxy monomers (AEMs) was studies using Potentiostat (BioLogic SP-200) instrument as designated in our prior reports. ${ }^{\mathbf{1 1 , 1 2}}$ In order to get more accuracy and reproducibility of experimental data, the electrochemical studies were performed triply at each tested concentration of the AEM1 and AEM2 and mean values are reported.

\subsection{Computational details}

For DFT study, both AEM1 and AEM2 were geometrically optimized using B3LYP/6-31+G(d,p) level in both gas phase and in aqueous solution as described elsewhere. All calculations were performed using the G09 suite program. ${ }^{21-28}$ To validate the

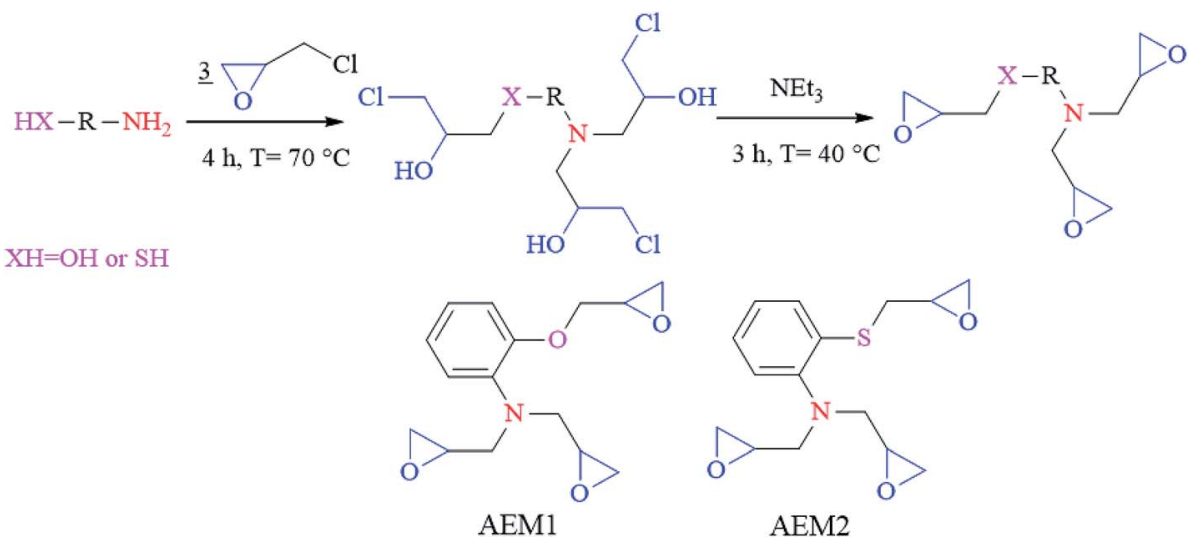

Fig. 1 Schematic outline for the synthesis of two aromatic epoxy monomers AEM1 and AEM2. 
experimental results and to gain a deeper insight into the reactivity of the studied AEM1 and AEM2 compounds, the calculated quantum global parameters, which were extracted based on the values of the highest occupied and lowest unoccupied molecular orbitals ( $E_{\text {Hомо }}$ and $E_{\text {LUMO }}$ ) were used. Different DFT parameters are calculated as follows: ${ }^{29-43}$

The ionization potential:

$$
I=-E_{\text {номо }}
$$

The electron affinity:

$$
A=-E_{\mathrm{LUMO}},
$$

The energy difference between $E_{\mathrm{Lumo}}$ and $E_{\mathrm{HOMO}}$,

$$
\Delta E=\left(E_{\mathrm{HOMO}}-E_{\mathrm{LUMO}}\right),
$$

The electronegativity:

$$
\chi=(I+A) / 2,
$$

The global hardness:

$$
(\eta=(I-A) / 2) \text { and softness }(\sigma=1 / \eta),
$$

The fraction of electrons transferred:

$$
\Delta N=\frac{\varphi_{\mathrm{Fe}}-\chi_{\mathrm{inh}}}{2\left(\eta_{\mathrm{Fe}}+\eta_{\mathrm{inh}}\right)},
$$

The initial molecule-metal interaction energy:

$$
\Delta \psi=\frac{\left(\chi_{\mathrm{Fe}}-\chi_{\mathrm{inh}}\right)^{2}}{2\left(\eta_{\mathrm{Fe}}+\eta_{\mathrm{inh}}\right)},
$$

The electron transfer electron back-donation:

$$
\Delta E_{\text {back-donation }}=-\frac{\eta}{4}
$$

where $\varphi_{\mathrm{Fe}}, \chi_{\mathrm{Fe}}$ and $\eta_{\mathrm{Fe}}$ are the work function, electronegativity and hardness of the iron, respectively. In this study, three different plans namely, (100), (110) and (111) were considered for the interaction with AEM1 and AEM2. The work function values of (100), (110) and (111) are 3.91, 4.82 and $3.88 \mathrm{eV}$, respectively. The electronegativity $\left(\chi_{\mathrm{Fe}}\right)$ and hardness $\left(\eta_{\mathrm{Fe}}\right)$ of iron are selected as 7.0 and $0 \mathrm{eV}$, respectively.

\subsection{Molecular dynamics simulation}

The interaction between AEM1 and AEM2 in their neutral as well as in their protonated (cationic) forms and metal surface was studied employing the molecular dynamics (MD) simulations. MD simulations were carried out using Forcite module of Materials Studio 8.0 program developed by BIOVIA Inc. MD simulations were done in a simulation box of $1.98 \mathrm{~nm} \times$ $1.98 \mathrm{~nm} \times 4.01 \mathrm{~nm}$ size with periodic boundary conditions. The box consisted of a lower Fe slab and a upper solvent layer (containing 500 water molecules and one inhibitor molecule of AEM1 and AEM2). For the iron substrate, Fe (110) was selected as explored surface because it has a density packed structure and is the most stable. The Fe(110) surface was modelled with a six-layer slab model. In this model, there were 64 iron atoms (8 $\times 8$ ) in each layer of unit cell. Particulars of similar simulations have also been documented in our aforementioned publications. ${ }^{44-48}$

\section{Results and discussion}

\subsection{Electrochemical measurements}

3.1.1. Open circuit potential (OCP). Fig. 2 represents the OCP versus time (for $1800 \mathrm{~s}$ ) curves for dissolution of metal in acidic medium with and without AEM1 and AME2. Formation of straight lines showed the establishment of steady sate potential and dissolution of surface oxide layers of $\mathrm{Fe}_{2} \mathrm{O}_{3}$ and
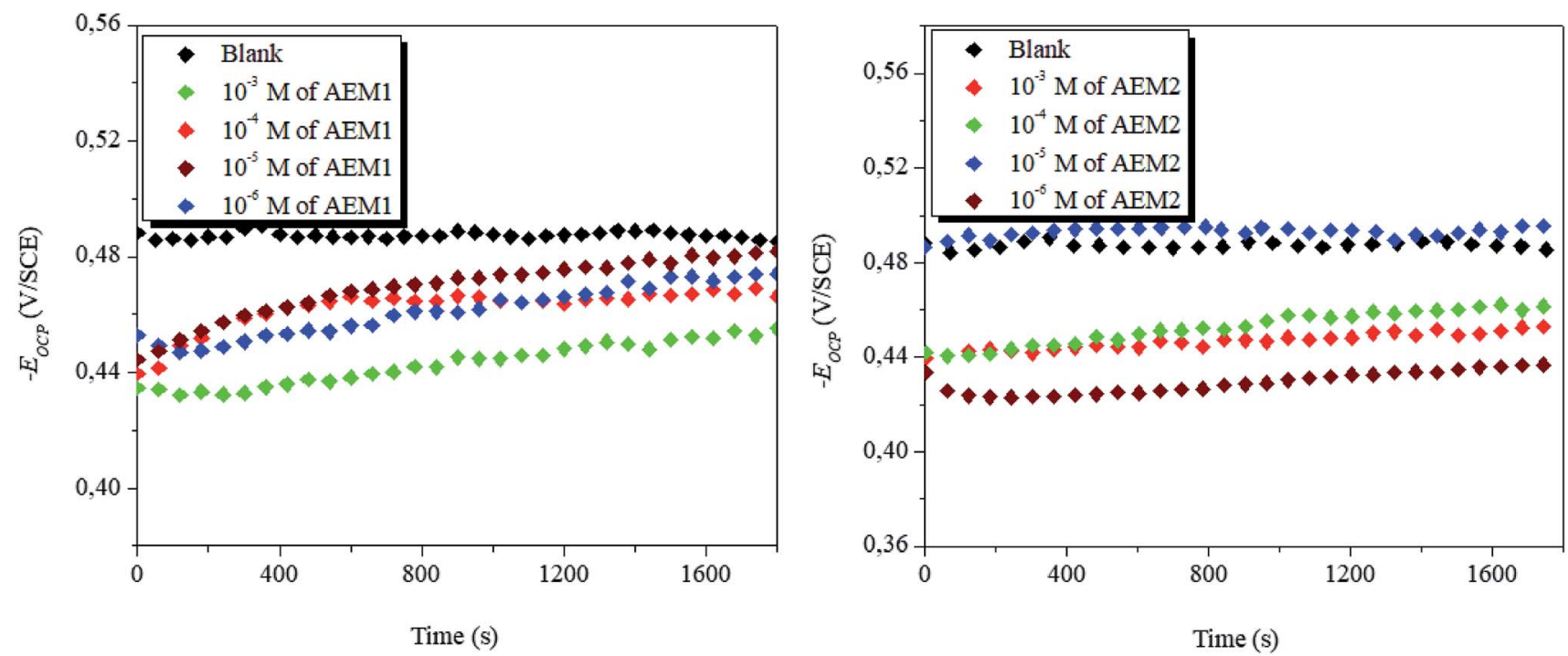

Fig. 2 Variation of $E_{\mathrm{OCP}}$ Vs. with time for carbon steel corrosion in $1 \mathrm{M} \mathrm{HCl}$ with and without AEM1 and AEM2 molecules at $298 \mathrm{~K}$. 
$\mathrm{Fe}_{3} \mathrm{O}_{4} \cdot{ }^{49}$ It is also observable that at most of the tested concentrations, OCP versus time curves are shifted towards more positive (anodic) directions. This implies that AEM1 and AEM2 are acted as predominantly anodic type inhibitors with predominant anticorrosive effect on anodic reaction. ${ }^{49}$

3.1.2. PDP study. The anodic and cathodic polarizations curves with and without AEMs are shown in Fig. 3 and PDP parameters are presented in Table 1. The surface coverage values at different concentrations of the AEMs were derived by dividing the percentage of efficiency by 100 . Extrapolation of the linear segments of the PDP curves gives the values of $i_{\text {corr }}$ through which inhibition efficiency $\left(\eta_{\mathrm{PDP}} \%\right)$ of AEMs was calculated as follows: ${ }^{14,16}$

$$
\eta_{\mathrm{PDP}} \%=\left(1-\frac{i_{\text {corr }}}{i_{\text {corr }}^{0}}\right) \times 100
$$

whereas, $i_{\text {corr }}^{0}$ and $i_{\text {corr }}$ represent the corrosion current densities without and with the AEMs correspondingly.

From the results it can be seen that $E_{\text {corr }}$ values for inhibited cases did not showed any significant change as compared to the $E_{\text {corr }}$ value of uninhibited case which implies that both AEM1 and AEM2 acted as mixed type corrosion inhibitors. Observation of the results showed that presence of the AEMs affected both anodic as well as cathodic reactions without affecting the common characteristics of PDP curves. ${ }^{50}$ This observation showed that AEM1 and AEM2 inhibit metallic corrosion by blocking the active sites without affecting mechanism of anodic and cathodic reactions. Further, it can also be seen that at most of the studied concentrations the anodic Tafel slope values $\left(\beta_{\mathrm{a}}\right)$ showed slightly higher shift as compared to the values of cathodic Tafel slope values $\left(\beta_{\mathrm{c}}\right)$ which suggested that both AEM1 and AEM2 have marked effect on anodic dissolution as compared to the cathodic hydrogen evolution reaction. It can also be noted that values of $E_{\text {corr }}$ are shifted towards more positive i.e. anodic direction with the presence the different concentration of AEMs. On this basis, it can be assumed that AEMs are acted as mixed type inhibitors with anodic predominance. Blocking of the active sites of metals can be resulted due to the adsorption of the AEM1 and AEM2 can using their several heteroatoms ( $\mathrm{N}, \mathrm{S}$ and $\mathrm{O}$ ) that offer non-bonding electrons and aromatic rings that offer $\pi$-electrons for metal-inhibitor interactions. Apart from the metal-inhibitors (AEMs) interactions, presence of heteroatoms in the form of polar functional group(s), enhances the solubility of the investigated inhibitor molecules. ${ }^{51}$

3.1.3. EIS study. The Nyquist plots for metal dissolution in $1 \mathrm{M} \mathrm{HCl}$ with and without AEM1 and AEM2 are presented in Fig. 4. It is easy to notice that all these Nyquist plots curves present a single capacitive loop in the frequency range of 100 $\mathrm{kHz}$ to $10 \mathrm{mHz}$, which is usually related to charge transfer phenomenon. ${ }^{52}$ The imperfection in the semicircle is resulted because of the frequency dispersion that resulted mainly due to the rough and inhomogeneous metallic surfaces. ${ }^{53}$ Careful observation of the Nyquist plots showed that diameters of the plots are increasing on increasing the concentration of AEM1 and AEM2 and maximum increase was observed at $10^{-3} \mathrm{M}$ concentration. This observation suggested that resistance for the metallic corrosion in acidic medium of $1 \mathrm{M} \mathrm{HCl}$ is increasing on increasing the concentration of AEM1 and AEM2. The fitted Nyquist and Bode plots and equivalent circuit used far the evaluation of EIS parameters are shown in Fig. 5. The CPE is defined as the below eqn (10): ${ }^{54,55}$

$$
Z_{\mathrm{CPE}}=Y_{0}^{-1}(i \omega)^{-n}
$$

In the above equation, all symbols have their usual meaning. ${ }^{45}$. The capacitance values $\left(C_{\mathrm{dl}}\right)$ is calculated using eqn (11): $: 56,57$

$$
C_{\mathrm{d} 1}=\left(Y_{0} R_{\mathrm{ct}}^{1-n}\right)^{1 / n}
$$
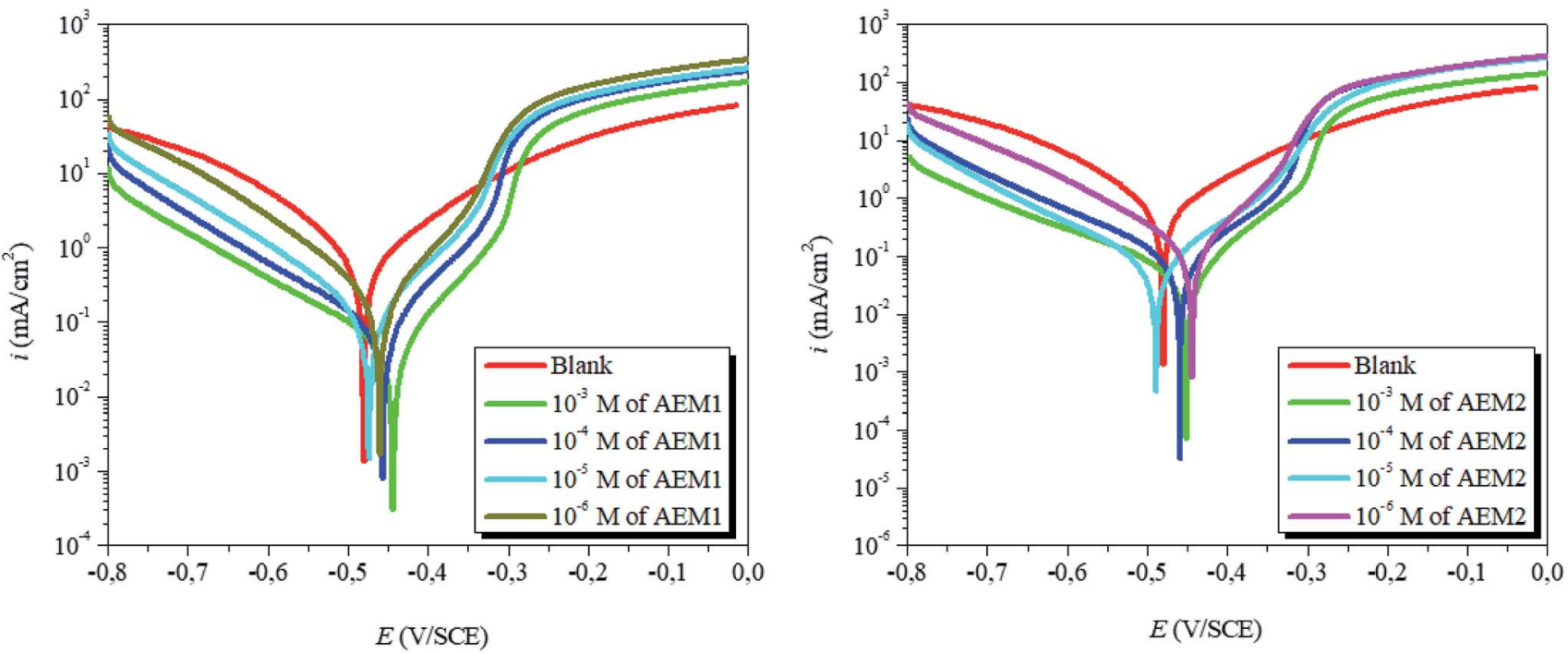

Fig. 3 PDP curves for carbon steel corrosion in $1 \mathrm{M} \mathrm{HCl}$ solution in the absence and presence of different concentrations of aromatic epoxy monomers AEM1 and AEM2 at $298 \mathrm{~K}$. 
Table 1 PDP parameters $( \pm S D)$ for carbon steel corrosion in $1 \mathrm{M} \mathrm{HCl}$ solution in the absence and presence of different concentrations of AEM1 and AEM2

\begin{tabular}{lllllll}
\hline Inh & $C(\mathrm{M})$ & $E_{\text {corr }}(\mathrm{mV})$ & $i_{\text {corr }}\left(\mu \mathrm{A} \mathrm{cm}^{-2}\right)$ & $\beta_{\mathrm{a}}\left(\mathrm{mV} \mathrm{dec}^{-1}\right)$ & $-\beta_{\mathrm{c}}\left(\mathrm{mV} \mathrm{dec}^{-1}\right)$ & $\eta \%$ \\
\hline Blank & - & -473.80 & $916.6( \pm 1.78)$ & $163.6( \pm 1.10)$ & $155.0( \pm 1.33)$ & - \\
AEM1 & $10^{-3}$ & -443.94 & $058.96( \pm 1.56)$ & $097.8( \pm 1.08)$ & $180.1( \pm 1.12)$ & 93.6 \\
& $10^{-4}$ & -457.68 & $097.75( \pm 1.72)$ & $102.2( \pm 1.11)$ & $183.0( \pm 1.17)$ & 89.3 \\
& $10^{-5}$ & -474.14 & $179.68( \pm 1.85)$ & $116.0( \pm 1.13)$ & $155.9( \pm 1.07)$ & 80.1 \\
AEM2 & $10^{-6}$ & -456.89 & $251.78( \pm 1.74)$ & $081.3( \pm 1.07)$ & $141.1( \pm 1.35)$ & 72.5 \\
& $10^{-3}$ & -451.26 & $032.88( \pm 1.55)$ & $73.90( \pm 1.18)$ & $166.1( \pm 1.25)$ & 0.801 \\
& $10^{-4}$ & -459.41 & $094.77( \pm 1.65)$ & $102.7( \pm 1.12)$ & $169.2( \pm 1.14)$ & 89.4 \\
& $10^{-5}$ & -489.01 & $107.53( \pm 1.16)$ & $134.9( \pm 1.20)$ & $172.1( \pm 1.37)$ & 0.964 \\
& $10^{-6}$ & -444.30 & $254.31( \pm 1.62)$ & $134.8( \pm 1.16)$ & $171.4( \pm 1.18)$ & 0.896 \\
& & & & & &
\end{tabular}

The inhibition efficiency $\eta_{\mathrm{EIS}} \%$ is calculated using the values of polarization resistance $R_{\mathrm{P}}$ using following relationship:

$$
\eta_{\mathrm{EIS}}(\%)=\frac{R_{\mathrm{P}}-R_{\mathrm{P}}^{0}}{R_{\mathrm{P}}} \times 100
$$

where, $R_{\mathrm{P}}^{0}$ and $R_{\mathrm{P}}$ are the polarization resistances without and with AEMs, respectively. As can be seen from Table 2 , the $R_{\mathrm{P}}$ values are increasing on increasing the AEMs concentrations. It can also be seen that increase in $R_{\mathrm{P}}$ value at tested concentrations of AEMs are relatively greater of AEM2 as compared to the AEM1 which showed that AEM2 is better corrosion inhibitor as compared to the AEM1. ${ }^{58}$ The high inhibition efficiency of the AEM2 is might be resulted due to the presence of less electronegative sulfur in its molecular structure atom that generally offers strong bonding with the metallic surface. AEM1 and AEM2 showed that highest inhibition efficiencies of $94.3 \%$ and 95.4\% respectively. Moreover, the $C_{\mathrm{dl}}$ values diminish on enhancing the concentration for the AEMs which is resulted from the increase in the thickness of the protective layer and/or the decrease in local dielectric constant. ${ }^{59}$ Bode modulus plots with and without aromatic epoxy monomers (AEMs) are given in
Fig. 6. Analyze of the figure displays that the magnitude of slope values for the inhabited (by AEMs) curves are greater than that of the uninhibited curve. Among the investigated AEMs, AEM2 (Fig. 6b) showed higher slope value than that of AEM1 (Fig. 6a) which implies that AEM2 has higher effectiveness towards the interaction with metal surface as compared to the AEM1.

The corresponding Bode plots for the corrosion of metal in acidic medium are given in Fig. $6 \mathrm{c}$ and $d$, that show a single maxima in the absence and presence of all concentrations of AEM1 and AEM2 which is a common characteristics of carbon steel corrosion in acidic medium. ${ }^{60}$ Increase in the phase angle values of inhibited (by AEMs) Bode plots is resulted due to increase in the metallic surface smoothness due to the adsorption of AEM1 and AEM2 at the interface of metal and electrolyte. ${ }^{60}$

\subsection{Adsorption studies}

In the present study, adsorption behavior of AEM1 and AEM2 is investigated using several commonly used adsorption isotherm models among which most frequently used Langmuir
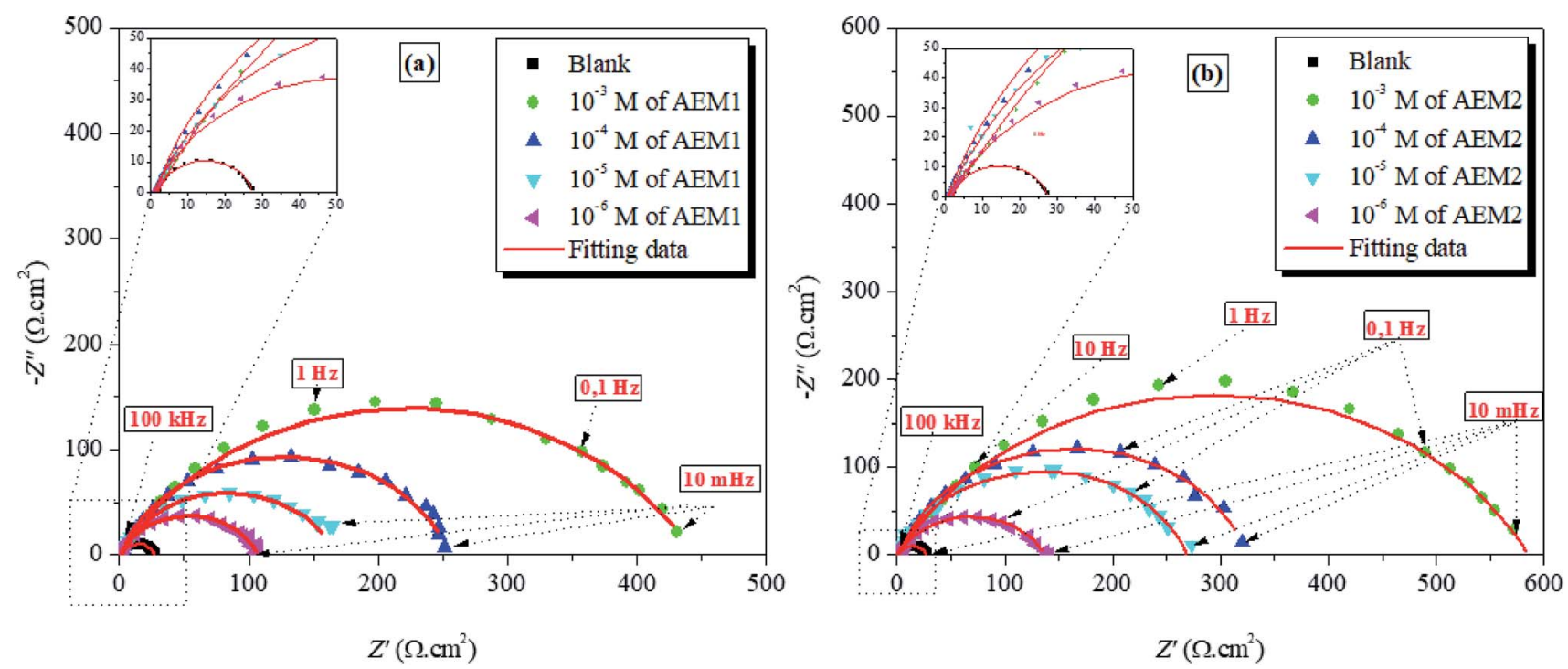

Fig. 4 Nyquist ( $a$ and b) diagrams for carbon steel in $1 \mathrm{M} \mathrm{HCl}$ solution in the absence and presence of different concentrations of aromatic epoxy monomers AEM1 and AEM2 at $298 \mathrm{~K}$. 

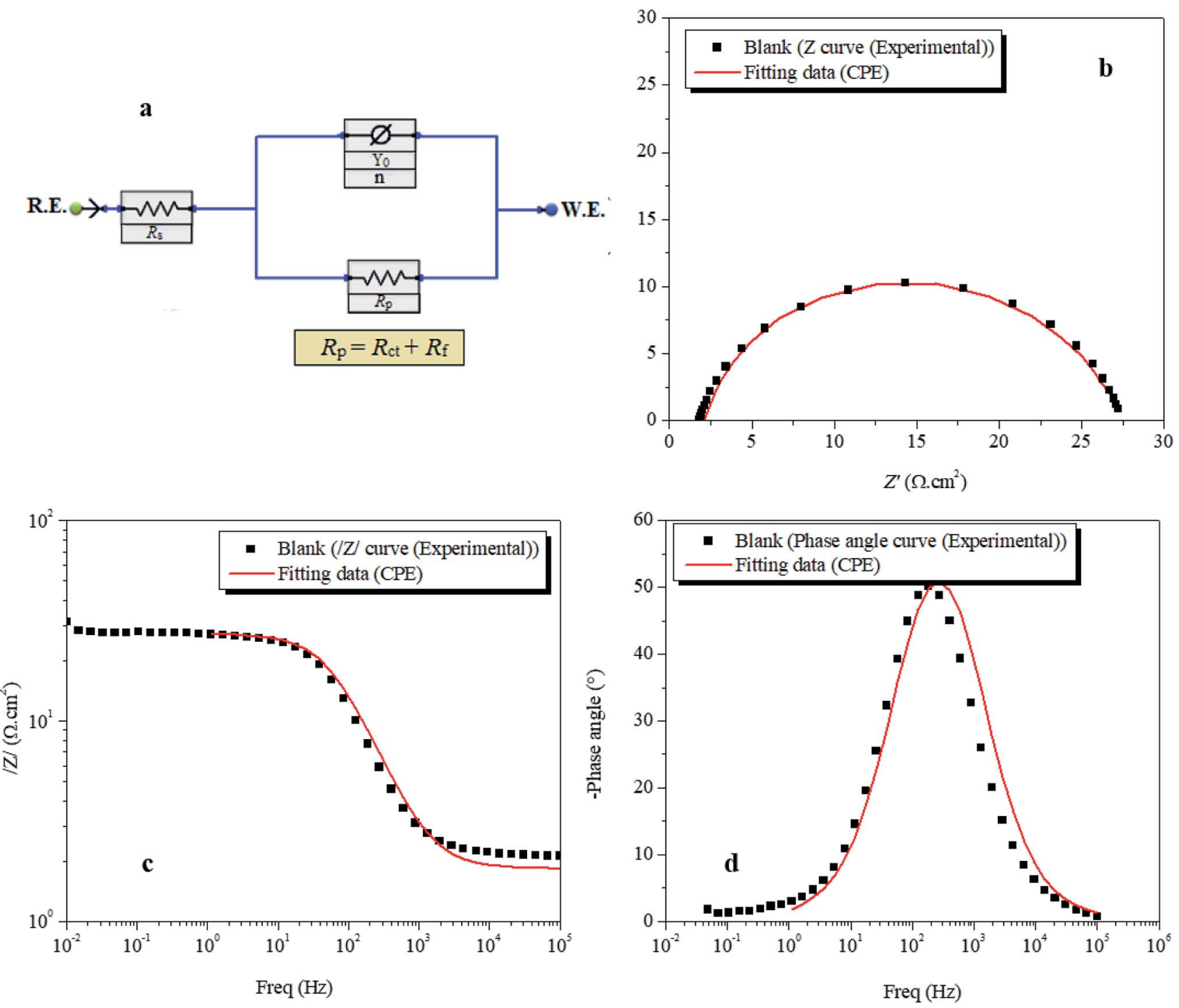

Fig. 5 Equivalent circuit model used to fit the EIS data.

adsorption isotherm gave the best fit. ${ }^{61}$ The linear form of Langmuir adsorption isotherm is represented in eqn (13):

$$
K_{\mathrm{ads}} C_{\mathrm{inh}}=\frac{\theta}{1-\theta}
$$

In which $C_{\mathrm{inh}}$ is the concentration of the compound, $\theta$ is surface coverage degree and $K_{\text {ads }}$ is the equilibrium constant. The association between $C_{\mathrm{inh}}$ and $C_{\mathrm{inh}} / \theta$ yielded straight lines with intercepts of $K_{\text {ads }}$ as shown in Fig. SI $3 . \dagger$ From the $K_{\text {ads }}$ values, the $\Delta G_{\text {ads }}$ values were calculated using eqn (14) and (15): ${ }^{62}$

Table 2 EIS parameters $( \pm S D)$ for carbon steel corrosion in $1 \mathrm{M} \mathrm{HCl}$ solution in the absence and presence of different concentrations of AEM1 and AEM2

\begin{tabular}{|c|c|c|c|c|c|c|c|c|}
\hline Inh & $C(\mathrm{M})$ & $R_{\mathrm{s}}\left(\Omega \mathrm{cm}^{2}\right)$ & $R_{\mathrm{P}}\left(\Omega \mathrm{cm}^{2}\right)$ & $n$ & $C_{\mathrm{dl}}\left(\mu \mathrm{F} \mathrm{cm}^{-2}\right)$ & $\eta \%$ & $\theta$ & $\chi^{2}$ \\
\hline Blank & - & $1.81( \pm 0.03)$ & $25( \pm 1.52)$ & $0.682( \pm 0.01)$ & $485.8( \pm 0.004)$ & - & - & 0.056 \\
\hline \multirow[t]{3}{*}{ AEM1 } & $10^{-3}$ & $1.44( \pm 0.07)$ & $441.3( \pm 1.85)$ & $0.842( \pm 0.01)$ & $103.4( \pm 0.008)$ & 94.3 & 0.943 & 0.028 \\
\hline & $10^{-5}$ & $1.13( \pm 0.05)$ & $160.3( \pm 1.45)$ & $0.768( \pm 0.03)$ & $216.2( \pm 0.003)$ & 84.4 & 0.844 & 0.044 \\
\hline & $10^{-6}$ & $0.98( \pm 0.13)$ & $106.4( \pm 0.96)$ & $0.762( \pm 0.01)$ & $346.3( \pm 0.009)$ & 76.5 & 0.765 & 0.186 \\
\hline \multirow[t]{2}{*}{ AEM2 } & $10^{-3}$ & $2.12( \pm 0.07)$ & $584.3( \pm 1.62)$ & $0.881( \pm 0.02)$ & $102.1( \pm 0.001)$ & 95.4 & 0.954 & 0.225 \\
\hline & $10^{-6}$ & $0.45( \pm 0.08)$ & $136.5( \pm 0.57)$ & $0.798( \pm 0.01)$ & $316.6( \pm 0.007)$ & 81.7 & 0.817 & 0.257 \\
\hline
\end{tabular}



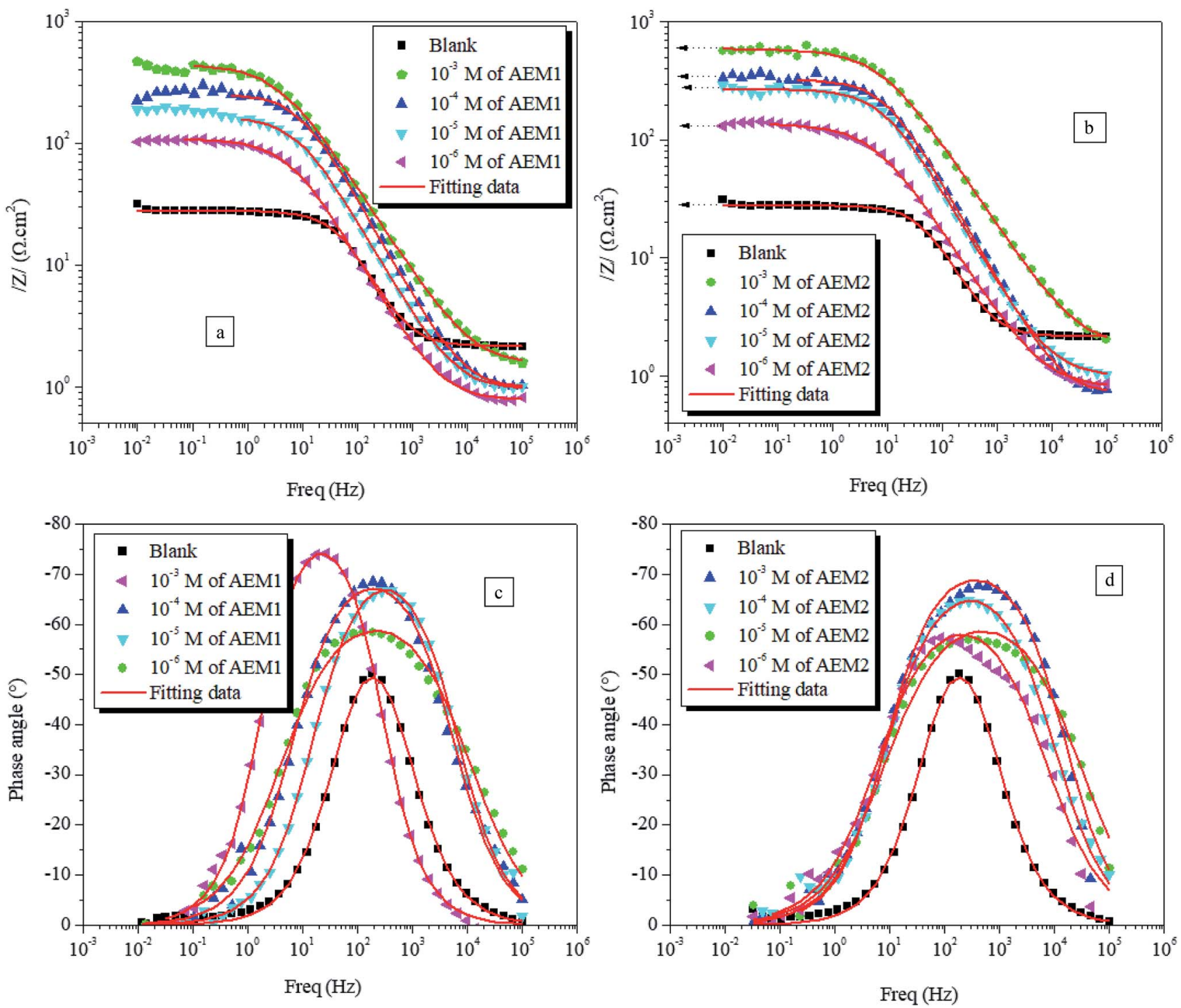

Fig. 6 Bode frequency ( $a$ and $b$ ) and phase angle (c and d) plots for carbon steel corrosion in the absence and presence of different concentrations of AEM1 and AEM2 at $298 \mathrm{~K}$.

$$
\begin{aligned}
K_{\mathrm{ads}} & =\frac{1}{55.5} \exp \left(\frac{-\Delta G_{\mathrm{ads}}}{R T}\right) \\
\Delta G_{\mathrm{ads}} & =-R T \ln \left(55.5 K_{\mathrm{ads}}\right)
\end{aligned}
$$

where, $R$ represents universal gas constant, value 55.55 is the molar concentration of water (M) and $T$ is an absolute temperature. Table SI $1 \uparrow$ provides the values of $K_{\text {ads }}$ and $\Delta G_{\text {ads }}$ obtained for the adsorption of the AEMs on the carbon steel surface. Generally, high negative value of $\Delta G_{\text {ads }}$ and high positive high value of $K_{\text {ads }}$ are associated with high inhibitor effectiveness. It is well known that value of $\Delta G_{\text {ads }}$ either equal to $-40 \mathrm{~kJ} \mathrm{~mol}^{-1}$ or more negative is consistent with chemisorption. ${ }^{61} \Delta G_{\text {ads }}$ value in the range of/or more positive than $-20 \mathrm{~kJ} \mathrm{~mol}^{-1}$ is associated with a physisorption (electrostatic) interaction. ${ }^{\mathbf{6 1}}$ The calculated $\Delta G_{\text {ads }}$ values for AEM1 and AEM2 are varied between -42.03 and $-44.20 \mathrm{~kJ} \mathrm{~mol}^{-1}$ which indicates that both investigated inhibitors adsorb on metallic surface mostly via chemisorption mechanism. ${ }^{63-65}$

\subsection{Effect of temperature}

The inhibition performance of AEMs at their optimum concentrations was tested at different temperatures $(298,308$, 318 and $328 \mathrm{~K}$ ) using PDP measurements and results are presented in Fig. SI 4 and Table SI $2 . \dagger$ It can be see that increase in temperature causes significant increase in the $i_{\text {corr }}$ without affecting the common features of polarization curves. This is due to the desorption of adsorbed AEMs molecules from the metallic surface at elevated temperatures. ${ }^{45}$ The effect of temperature can be demonstrated using Arrhenius and transition state equations: ${ }^{66-68}$

$$
i_{\text {corr }}=A \exp \left(-\frac{E_{\mathrm{a}}}{R T}\right)
$$




$$
i_{\text {corr }}=\frac{R T}{h N} \exp \left(\frac{\Delta S_{\mathrm{a}}}{R}\right) \exp \left(-\frac{\Delta H_{\mathrm{a}}}{R T}\right)
$$

where, $A$ is the pre-exponential factor, $\Delta S_{\mathrm{a}}$ is the entropy of activation, $\Delta H_{\mathrm{a}}$ is the enthalpy, $N$ is the Avogadro number, $h$ is the Planck constant. Results (Fig. SI $5 \dagger$ ) showed that $E_{\text {a values }}$ are higher in the presence of AEM1 and AEM2 as compared to in their absence which implies that both AEM1 and AEM2 adsorb through physisorption mechanism that takes place during the initial stage of the metal-inhibitors interactions. ${ }^{69}$ Positive values of $\Delta H_{\mathrm{a}}$ suggested that interaction of AEM1 and SEM2 with metallic surface is an endothermic process whereas large negative values of $\Delta S_{\mathrm{a}}$ suggested the creation of active complex and dissociation of the complex is the rate determining step. ${ }^{70-72}$

\subsection{Comparative efficiency}

Literature study reveals that few of the aromatic epoxy monomers based organic inhibitors have been evaluated for their anti-corrosive behavior for metals and alloys in different electrolytic media. ${ }^{\mathbf{1 4 - 1 6 , 7 1 , 7 2}}$ Inhibition effectiveness of some common representatives of the similar inhibitors is presented in Table 3. It can be seen that these types of compounds are acted as good corrosion inhibitors and their molecules structures contain $\mathrm{N}$, $\mathrm{O}, \mathrm{S}$ and/or $\mathrm{P}$ heteroatoms along with the aromatic ring(s).

\subsection{Theoretical studies}

3.5.1. Quantum chemical calculation. Fig. 7 and 8 show the optimized structures, the frontier molecular orbitals and electrostatic potential maps of the neutral and the protonated species of the studied compound in aqueous solution. According to FMO theory, the chemical reaction mainly occurred on HOMO and LUMO sites of the molecules. The values of the HOMO and LUMO energies give additional understanding related to the ability of electron donation and acceptation to and from the metal surface. In this sense, the electron dissemination of HOMO and LUMO is a challenging way to forecast the reactivity and, therefore, the capability of the inhibitor compounds to adsorb onto the metal surface. Depending on FMO theory, higher value of $E_{\mathrm{HOMO}}$ signifies that the inhibitor has a higher ability to transfer its electrons to suitable acceptor molecule whereas converse it true for $E_{\text {LUMO }}{ }^{73-76}$ Therefore, a lower $E_{\text {LUMO }}$ value implies that inhibitor is more plausible to accept electrons. ${ }^{77}$ The energy gap $(\Delta E)$ is a very useful quantum parameter, which measures the chemical reactivity and complexation with the metal surfaces. ${ }^{78}$ It was

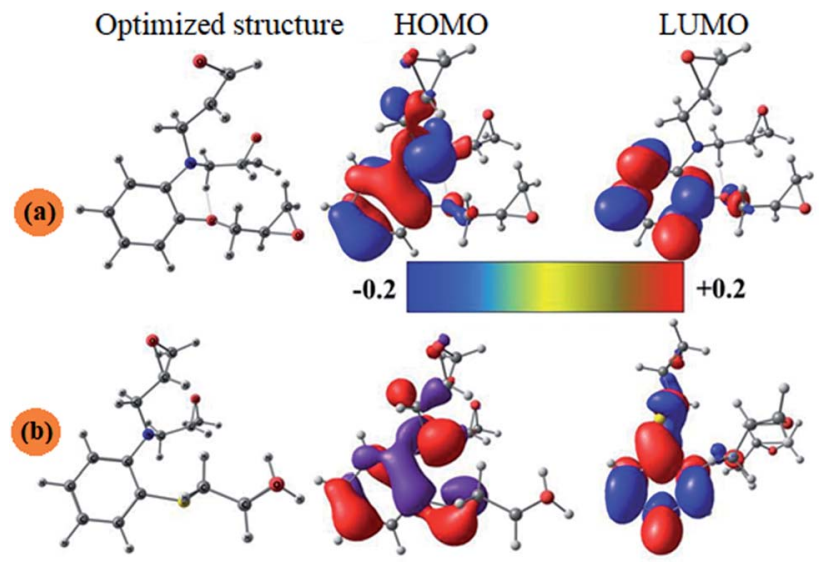

Fig. 7 The optimized molecular structures, $\mathrm{HOMO}$ and LUMO of the neutral inhibitor molecules AEM1 (a) and AEM2 (b) using B3LYP using functional and $6-31+G(d, p)$ basis set.

found that the lower value of the energy gap is generally correlated with high chemical reactivity. The lower energy gap inhibitor, the higher inhibition efficiency one..$^{75,79,80}$

Table 4 displays the computed results of total energies, dipole moments, $E_{\text {Номо }}$ and $E_{\text {LuMO }}$, and the estimated quantum parameters of the protonated and no protonated structures of the investigated inhibitors in both gas phase and in aqueous medium. In section of Table 4 indicates that the $E_{\text {HоMO }}$ of AEM2 in its protonated form, in both media, is higher than that of AEM1, which leads us to expect that the protection effectiveness of AEM2 is superior to AEM1. This finding is healthy interrelated with the obtained experimental results (AEM2 > AEM1). Whereas, the order is reserved when the nonprotonated species are considered. It is also found that the trend in $E_{\text {LUMO }}$ values of the protonated species in aqueous phase follows the order: AEM2 < AEM1, which is also well correlated with the experimental findings. On the other hand, there is no correspondence among the experimental results and computed ones when the non-protonated species were taken into account. Based on these results, thereafter, our attention will be focused on the on the results obtained for the protonated species in the aqueous which is similar to the corrosion medium used in the experimental study.

As indicated from Table 4, the values of the energy gap between $E_{\text {LUMO }}$ (ability to accept) and $E_{\text {HOMO }}$ (ability to donate) follow the order AEM2 (5.271 eV) < AEM1 (5.463 eV). This finding reflects that AEM2 has the higher inhibition efficiency than AEM1, because lower energy gap causes the improvement

Table 3 Inhibition efficiency comparisons for some traditional corrosion inhibitors

\begin{tabular}{|c|c|c|c|c|c|}
\hline Type of corrosion inhibitor & Type of solution & $C(\mathrm{M})$ & Type of substrate & $\eta_{\text {Max }}(\%)$ & Ref. \\
\hline Hexa(3-methoxy propan-1,2-diol)cyclotri-phosphazene & $3 \% \mathrm{NaCl}$ & $10^{-3}$ & Carbon steel & 99.0 & 14 \\
\hline Triglycidyl ether of triethoxytriazine & $1 \mathrm{M} \mathrm{HCl}$ & $10^{-3}$ & Carbon steel & 88.0 & 15 \\
\hline Tetraglycidyl-1,2-aminobenzamide & $1 \mathrm{M} \mathrm{HCl}$ & $10^{-3}$ & Carbon steel & 96.0 & 16 \\
\hline$S, S^{\prime}$-Diglycidyl $O, O^{\prime}$-dicarbonodithioate of bisphenol A & $1 \mathrm{M} \mathrm{HCl}$ & $10^{-3}$ & Carbon steel & 96.0 & 71 \\
\hline Octaglycidylether tetra-aniline para methylene dianiline & $0.5 \mathrm{M} \mathrm{H}_{2} \mathrm{SO}_{4}$ & $10^{-3}$ & Mild steel & 98.0 & 72 \\
\hline
\end{tabular}



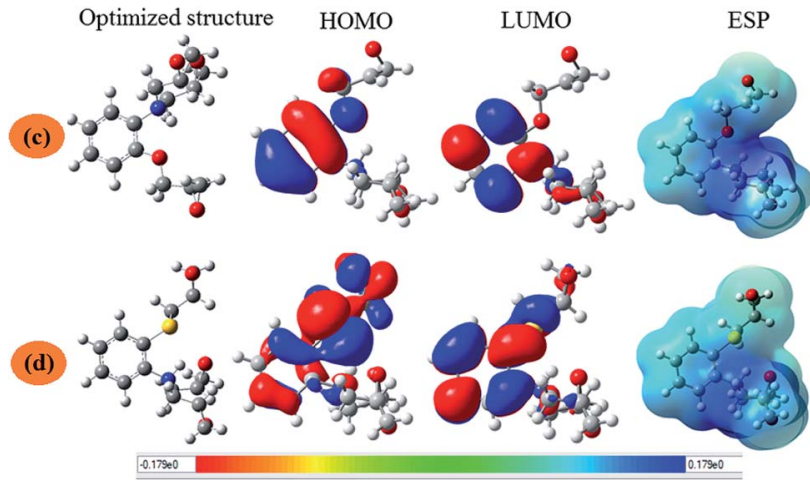

Fig. 8 The optimized molecular structures, HOMO and LUMO of the protonated inhibitor molecules $A E M 1-H^{+}$(c) and $A E M 2-H^{+}$(d) using B3LYP using functional and $6-31+G(d, p)$ basis set.

on molecular reactivity, which facilitates reactivity. It is also found that the global hardness value of AEM1 (2.733 eV) inhibitor is greater than of the AEM2 molecule $(2.636 \mathrm{eV})$, therefore, the trend of the protection effectiveness of the investigated inhibitors as follows: AEM2 > AEM1.

The $\Delta N$ values were derived using eqn (6). It was previously reported that the aptitude of a compound to transference its electrons to or from the iron surface can be indicated by measuring the $\Delta N$ value. It was found that for $\Delta N>0$ case, the electron is transferred from inhibitor to metal and, vice versa, if $\Delta N<0 .{ }^{81-83,85}$ Our results (Table 4 ) show that, the positive values of $\Delta N$ on all iron planes (100), (110) and (111) are more positive for AEM2 (1.679, 2.879 and 1.640) than AEM1 (1.609, 2.852, 1.568). These results suggest the higherability of AEM2 to give electrons to the iron surface than AEM1. It is also found that the donation of electrons from the inhibitor to the 110 plan is the most positive among all cases. Sastri and Perumareddi ${ }^{84}$ was calculated $\Delta \psi$ using eqn (7). $\Delta \psi$ is also considered as an important property it is found that the trend in $\Delta \psi$ follow the order AEM2 (1.379 eV) > AEM1 (1.282 eV) (Table 4). This indicates that AEM2 molecule has an inhibition efficiency greater than AEM1 molecule, which also agrees with the experimental results.

The $\Delta E_{\text {back-donation }}\left(\Delta E_{\mathrm{b}-\mathrm{d}}\right)$ parameter was calculated using eqn (8). $\Delta E_{\mathrm{b}-\mathrm{d}}$ suggests that back-donation or retro-donation progression i.e. electron transfer from metal surface to inhibitor (AEMs) molecules. ${ }^{85}$ Eqn (8) implies that when the hardness $(\eta)$ of the inhibitor is higher than zero or $\Delta E_{\mathrm{b}-\mathrm{d}}$ is less than zero. The process is energetically favored. Our results displayed in Table 4 indicate that $\Delta E_{\mathrm{b}-\mathrm{d}}<0$, therefore, the charge transfer to an inhibitor followed by back-donation from the inhibitor is dynamically favorable. The calculated $\Delta E_{\mathrm{b}-\mathrm{d}}$ values follow the order AEM2 $(-0.659 \mathrm{eV})>$ AEM1 $(-0.683 \mathrm{eV})$, which also correlates with the experimental results.

Finally, the computed dipole moment of the investigated species in all proposed cases are also gathered in Table 4. Xianghong, et $a .^{86}$ reported that the high value of $\mu$ possibly increments the interactions between adsorbate and adsorbent. Results in Table 4 reveal that the dipole moments of the protonated AEM2 inhibitor in aqueous medium is 1.13 Debye and it is higher than that of the AEM1 molecule. Therefore, the inhibition efficiency trend may follow the order AEM2 > AEM1. Another important quantum index is the proton affinity (PA) ${ }^{87}$ Results presented in Table 4 showed that the proton affinity of AEM2- $\mathrm{H}^{+}$(Fig. 6b) is higher that of the AEM1- $\mathrm{H}^{+}$(Fig. 6a) which establishes that effectiveness of the AEMs obeyed the order: AEM2- $\mathrm{H}^{+}>$AEM1- $\mathrm{H}^{+}$. This finding is in good agreement with the reported experimental data. Results of $N$-protonated species in

Table 4 Quantum chemical parameters for the neutral and protonated forms of AEM1 and AEM2 in both gas phase and aqueous solution, calculated using B3LYP/6-311++G(d,p)

\begin{tabular}{|c|c|c|c|c|c|c|c|c|c|c|c|c|}
\hline & \multicolumn{4}{|c|}{ Neutral form } & \multicolumn{4}{|c|}{ Protonated forms (opened epoxy rings) } & \multicolumn{4}{|c|}{ Protonated forms (nitrogen atom) } \\
\hline & \multicolumn{2}{|c|}{ Gas phase } & \multicolumn{2}{|c|}{ Aqueous solution } & \multicolumn{2}{|l|}{ Gas phase } & \multicolumn{2}{|c|}{ Aqueous solution } & \multicolumn{2}{|l|}{ Gas phase } & \multicolumn{2}{|c|}{ Aqueous solution } \\
\hline E & -938.57 & -1261.55 & -938.59 & -1261.56 & -1167.99 & -1490.95 & -1168.01 & -1490.99 & -938.95 & -1261.93 & -939.03 & -1262.01 \\
\hline$\mu$ & 2.81 & 4.18 & 4.27 & 5.31 & 5.47 & 4.08 & 5.19 & 6.32 & 4.60 & 6.19 & 5.85 & 8.69 \\
\hline$\Delta E$ & 5.286 & 5.108 & 5.318 & 5.111 & 5.557 & 4.984 & 5.465 & 5.271 & 5.707 & 5.424 & 5.735 & 5.637 \\
\hline$I$ & 5.76 & 6.156 & 5.872 & 6.054 & 5.958 & 5.329 & 5.989 & 5.867 & 10.324 & 10.048 & 7.054 & 7.232 \\
\hline$A$ & 0.474 & 1.047 & 0.555 & 0.943 & 0.401 & 0.345 & 0.524 & 0.596 & 4.617 & 4.625 & 1.319 & 1.595 \\
\hline$\chi$ & 3.117 & 3.601 & 3.213 & 3.498 & 3.179 & 2.837 & 3.257 & 3.232 & 7.470 & 7.337 & 4.186 & 4.414 \\
\hline$\eta$ & 2.643 & 2.554 & 2.659 & 2.556 & 2.778 & 2.492 & 2.733 & 2.636 & 2.854 & 2.712 & 2.868 & 2.818 \\
\hline$\sigma$ & 0.378 & 0.392 & 0.376 & 0.391 & 0.36 & 0.401 & 0.366 & 0.379 & 0.350 & 0.369 & 0.349 & 0.355 \\
\hline${ }^{a} \mathrm{PA}$ & 202.1 & 205.4 & -40.6 & -39.8 & & & & & & & & \\
\hline
\end{tabular}

${ }^{a} \mathrm{PA}=E($ protonated $)-\left(E(\right.$ neutral $\left.)+E\left(\mathrm{H}^{+}\right)\right)\left(\right.$in kcal mol$\left.{ }^{-1}\right) ; E\left(\mathrm{H}^{+}\right)$in gas phase $=1.48 \mathrm{kcal} \mathrm{mol}^{-1}$ and in aqueous solution $=-275.12 \mathrm{kcal}^{\mathrm{mol}}{ }^{-1}$. 
aqueous solution have the same inhibition efficiency order as in the case of the neutral and the opened epoxy rings.

3.5.2. Molecular dynamics simulation. The nature of metal-AEMs interactions and orientations of AEMs on metallic surface was further studied using MD simulation method. The equilibrium configurations (top and side view) of the inhibitors in neutral and protonated forms adsorbed on the $\mathrm{Fe}(110)$ surface are shown in Fig. 9. It can be seen that the neutral inhibitors adsorb on the metal surface through the nitrogen $(\mathrm{N})$, oxygen (O), sulfur (S) atoms as well as the aromatic rings. The adsorption energy $\left(E_{\text {ads }}\right)$ for AEMS adsorption can be calculated as follow (18):

$$
E_{\text {ads }}=E_{\text {total }}-\left(E_{\text {surinh+water }}+E_{\text {inhinh+water }}\right)+E_{\text {water }}
$$

where, $E_{\text {total }}$ is denote the total energy related to metal-AEMs interactions, which include iron crystal, the adsorbed inhibitor molecule and solution; $E_{\text {surf+water }}$ and $E_{\text {inh+water }}$ are the potential energies of the system without the inhibitor and the system without the iron crystal, respectively; $E_{\text {water }}$ is the potential energy of the water molecules. The obtained $E_{\text {ads }}$ values are $-634.0,-263.1,-689.2$, and $-346.5 \mathrm{~kJ} \mathrm{~mol}^{-1}$ for AEM1, AEM1$\mathrm{H}^{+}$, AEM2, and AEM2- $\mathrm{H}^{+}$, respectively. Negative values of $E_{\text {ads }}$ indicate the spontaneous behaviour of metal-AEMs interactions. The more negative value of $E_{\text {ads }}$ for AEM2 as compared to the AEM1 indicates that later case has relatively strong probability of metal-inhibitor interactions as compared to former one. ${ }^{88}$ It can also be seen that $E_{\text {ads }}$ values are higher for neutral form of the AEMs as compared to the protonated form of the AEMs which implies that interactions between AEMs and metallic surface mostly followed the chemisorption mechanism. Effect of the temperature for AEM2 has also been demonstrated using MD simulations and result is shown in Fig. 10. The calculated values of $E_{\text {ads }}$ are $-689.2,-665.4$, -636.7 , and $-611.9 \mathrm{~kJ} \mathrm{~mol}^{-1}$ at $298 \mathrm{~K}, 308 \mathrm{~K}, 318 \mathrm{~K}$ and $328 \mathrm{~K}$, respectively. From the results it can be observe that increase in the temperature causes significant decrease in the values of $E_{\text {ads }}$ that can be resulted due to increase in the kinetic energy of the inhibitor molecules at elevated temperatures.

\subsection{Mechanism of corrosion inhibition}

On the basis of combined computational modeling and experimental results a simple inhibition mechanism can be proposed for carbon steel in hydrochloric acid medium. AEMs molecules in $\mathrm{HCl}$ can protonate and exit in their protonated forms as demonstrated as follows:

$$
\mathrm{AEMs}+\mathrm{HCl} \leftrightarrow[\mathrm{AEMs}-\mathrm{H}]^{+}+\mathrm{Cl}^{-}
$$

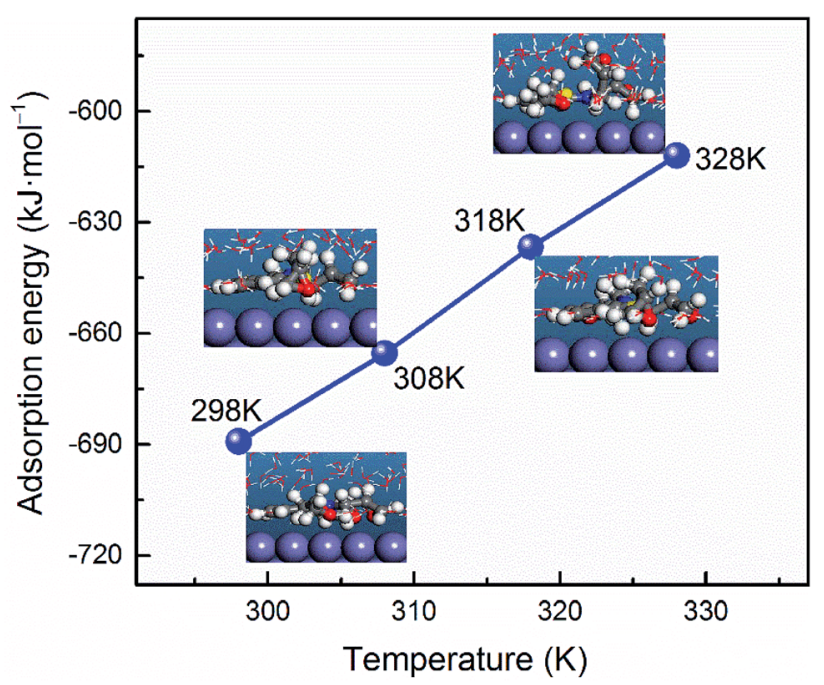

Fig. 10 Dependence of adsorption energy on the temperature for adsorbed AEM2 molecule on Fe(110).
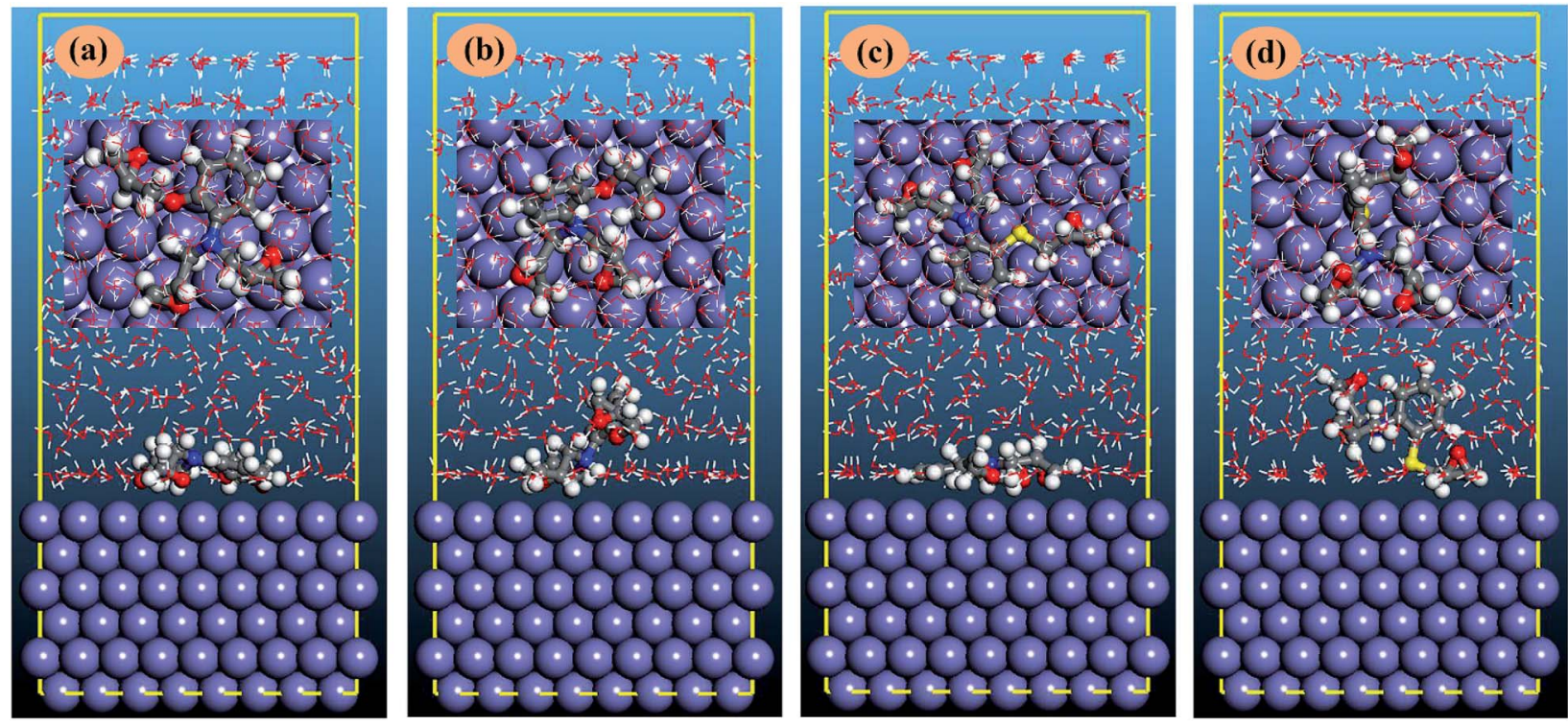

Fig. 9 The equilibrium configurations of (a) AEM1, (b) AEM1- $\mathrm{H}^{+}$, (c) AEM2, (d) AEM2- $\mathrm{H}^{+}$inhibitors adsorbed on Fe(110) surface. 


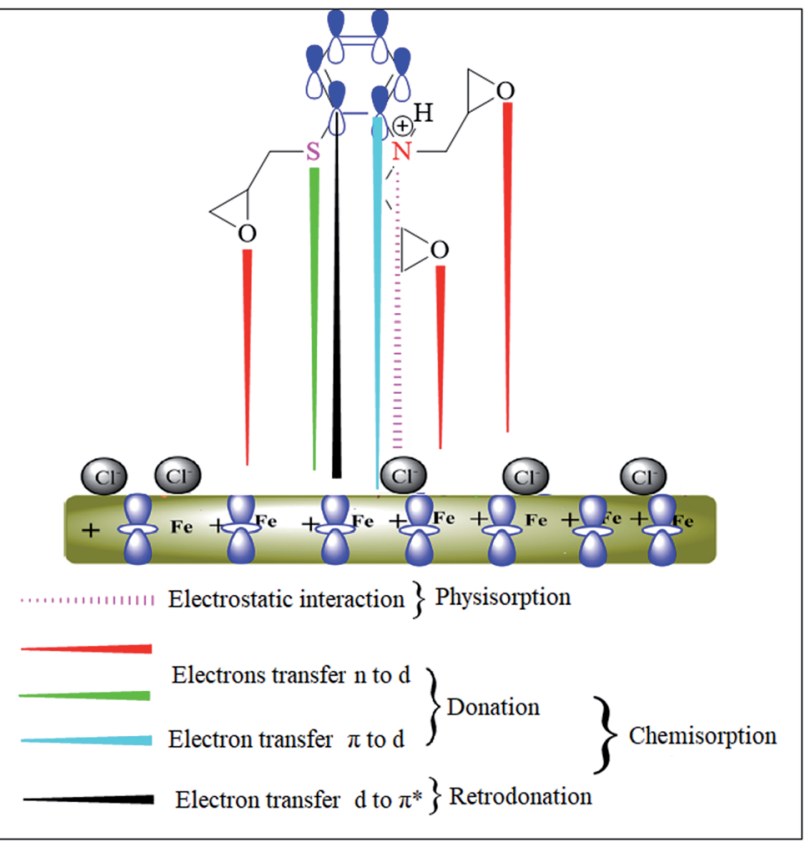

Fig. 11 Pictorial representation of adsorption of AEM2 on carbon steel surface in $1 \mathrm{M} \mathrm{HCl}$ solution.

Metallic surface becomes negatively charged due to adsorption of chloride ions that ultimately attracts the positively charged inhibitor molecules through electrostatic force of attractions. ${ }^{\mathbf{8 9}, 90}$ However, AEMs can interact chemically through several heteroatoms such as $\mathrm{N}, \mathrm{O}, \mathrm{S}$ atoms and aromatic rings that offer strong bonding with the metallic surface A possible mechanism of the adsorption of AEM on the steel surface is shown in Fig. 11.

\section{Conclusions}

From above experimental and theoretical studies, it can be concluded that:

(i) AEM1 and AEM2 acted as good inhibitors and their inhibition effectiveness increases with increasing their concentration.

(ii) The PDP results reveal that, the AEMs behave as mixedtype inhibitors with anodic predominance.

(iii) The EIS results suggested that, AEMs molecules protect the carbon steel from corrosion by the formation of a protective film at the metal-electrolyte interface.

(iv) Adsorption of the tested AEMs molecules obeyed Langmuir adsorption isotherm.

(v) Values of $\Delta G_{\text {ads }}$ suggested that AEM1 and AEM2 mainly interact through chemisorption mechanism.

(vi) The chemisorption mechanism was further supported by MD simulations study.

(vii) Theoretical results derived for neutral and protonated forms of the AEMs in both gas phase and aqueous solution indicated that AEM2 acted as is more efficient inhibitor than AEM1. (viii) The more negative value of $E_{\text {ads }}$ for AEM2 as compared to the AEM1 indicated that AEM2 acted as is more efficient inhibitor than AEM1.

\section{Conflicts of interest}

There are no conflicts to declare.

\section{Acknowledgements}

C. Verma thankfully acknowledge the North-West University (Mafikeng Campus) South Africa for providing financial assistance under postdoctoral fellowship scheme. Nuha Wazzan gratefully acknowledges King Abdulaziz University's High Performance Computing Centre (Aziz Supercomputer) for assisting with the calculations for this study. This research was partially supported by the National Natural Science Foundation of China (21706195), the Science and Technology Program of Guizhou Province (QKHJC2016-1149), and the Guizhou Provincial Department of Education Foundation (QJHKYZ2016105). We would like to thank the Laboratory of Metallurgical Analysis, Cetim Maroc Développement (Centre Technique des Industries de la Mécanique) and Quality Control Laboratory, Casablanca Aeronautics Group Figeac Aero. Aeronautical Technopole of Nouaceur, Mohammed V-Casablanca Airport, Morocco.

\section{References}

1 M. Murmu, S. K. Saha, N. C. Murmu and P. Banerjee, Effect of stereochemical conformation into the corrosion inhibitive behaviour of double azomethine based Schiff bases on mild steel surface in $1 \mathrm{~mol} \mathrm{~L}^{-1} \mathrm{HCl}$ medium: An experimental, density functional theory and molecular dynamics simulation study, Corros. Sci., 2019, 146, 134-151.

2 J. Haque, V. Srivastava, C. Verma, H. Lgaz, R. Salghi and M. A. Quraishi, N-Methyl-N, N, N-trioctylammonium chloride as a novel and green corrosion inhibitor for mild steel in an acid chloride medium: electrochemical, DFT and MD studies, New J. Chem., 2017, 41(22), 13647-13662.

3 R. Hsissou, O. Dagdag, S. Abbout, F. Benhiba, M. Berradi, M. El Bouchti and A. Elharfi, Novel derivative epoxy resin TGETET as a corrosion inhibition of E24 carbon steel in 1.0 M HCl solution. Experimental and computational (DFT and MD simulations) methods, J. Mol. Liq., 2019, 284, 182192.

4 A. Pandey, B. Singh, C. Verma and E. E. Ebenso, Synthesis, characterization and corrosion inhibition potential of two novel Schiff bases on mild steel in acidic medium, $R S C$ Adv., 2017, 7(74), 47148-47163.

5 A. Singh, K. R. Ansari, M. A. Quraishi, H. Lgaz and Y. Lin, Synthesis and investigation of pyran derivatives as acidizing corrosion inhibitors for N80 steel in hydrochloric acid: Theoretical and experimental approaches, J. Alloys Compd., 2018, 762, 347-362.

6 N. K. Gupta, M. A. Quraishi, C. Verma and A. K. Mukherjee, Green Schiff's bases as corrosion inhibitors for mild steel in 
$1 \mathrm{M} \mathrm{HCl}$ solution: experimental and theoretical approach, RSC Adv., 2016, 6(104), 102076-102087.

7 C. Verma, L. O. Olasunkanmi, I. B. Obot, E. E. Ebenso and M. A. Quraishi, 5-Arylpyrimido-[4, 5-b] quinoline-diones as new and sustainable corrosion inhibitors for mild steel in $1 \mathrm{M} \mathrm{HCl}$ : a combined experimental and theoretical approach, RSC Adv., 2016, 6(19), 15639-15654.

8 C. Verma, M. A. Quraishi, L. O. Olasunkanmi and E. E. Ebenso, L-Proline-promoted synthesis of 2-amino-4arylquinoline-3-carbonitriles as sustainable corrosion inhibitors for mild steel in $1 \mathrm{M} \mathrm{HCl}$ : experimental and computational studies, RSC Adv., 2015, 5(104), 85417-85430.

9 F. El-Hajjaji, M. Messali, M. M. de Yuso, E. RodríguezCastellón, S. Almutairi, T. J. Bandosz and M. Algarra, Effect of 1-(3-phenoxypropyl) pyridazin-1-ium bromide on steel corrosion inhibition in acidic medium, $J$. Colloid Interface Sci., 2019, 541, 418-424.

10 L. P. Chaudhari and S. N. Patel, Corrosion Inhibition Study of Expired Acetazolamide on Mild Steel in Dilute Hydrochloric Acid Solution, Journal of Bio- and TriboCorrosion, 2019, 5(1), 20.

11 O. Dagdag, O. Hamed, H. Erramli and A. El Harfi, Anticorrosive Performance Approach Combining an Epoxy Polyaminoamide-Zinc Phosphate Coatings Applied on Sulfo-tartaric Anodized Aluminum Alloy 5086, Journal of Bio- and Tribo-Corrosion, 2018, 4(4), 52.

12 O. Dagdag, A. El Harfi, L. El Gana, Z. Hlimi, H. Erramli, O. Hamed and S. Jodeh, The Role of Zinc Phosphate Pigment in the Anticorrosion Properties of Bisphenol A Diglycidyl Ether-Polyaminoamide Coating for Aluminum Alloy AA2024T3, Journal of Bio- and Tribo-Corrosion, 2019, 5(1), 7.

13 M. Galai, M. El Gouri, O. Dagdag, Y. El Kacimi, A. Elharfi and M. Ebn Touhami, New hexa propylene glycol cyclotiphosphazene as efficient organic inhibitor of carbon steel corrosion in hydrochloric acid medium, J. Mater. Environ. Sci., 2016, 7, 1562.

14 O. Dagdag, A. El Harfi, M. El Gouri, Z. Safi, R. T. Jalgham, N. Wazzan and U. P. Kumar, Anticorrosive properties of Hexa (3-methoxy propan-1, 2-diol) cyclotri-phosphazene compound for carbon steel in $3 \% \mathrm{NaCl}$ medium: gravimetric, electrochemical, DFT and Monte Carlo simulation studies, Heliyon, 2019, 5(3), e01340.

15 R. Hsissou, S. Abbout, A. Berisha, M. Berradi, M. Assouag, N. Hajjaji and A. Elharfi, Experimental, DFT and molecular dynamics simulation on the inhibition performance of the DGDCBA epoxy polymer against the corrosion of the E24 carbon steel in $1.0 \mathrm{M} \mathrm{HCl}$ solution, J. Mol. Struct., 2019, 1182, 340-351.

16 O. Dagdag, A. El Harfi, O. Cherkaoui, Z. Safi, N. Wazzan, L. Guo and R. T. Jalgham, Rheological, electrochemical, surface, DFT and molecular dynamics simulation studies on the anticorrosive properties of new epoxy monomer compound for steel in $1 \mathrm{M} \mathrm{HCl}$ solution, RSC Adv., 2019, 9(8), 4454-4462.

17 O. Dagdag, A. Essamri, L. El Gana, M. El Bouchti, O. Hamed, O. Cherkaoui and A. El Harfi, Synthesis, characterization and rheological properties of epoxy monomers derived from bifunctional aromatic amines, Polym. Bull., 2018, 1-15. 18 O. Dagdag, A. El Harfi, A. Essamri, A. El Bachiri, N. Hajjaji, H. Erramli and S. Jodeh, Anticorrosive Performance of New Epoxy-Amine Coatings Based on Zinc Phosphate Tetrahydrate as a Nontoxic Pigment for Carbon Steel in $\mathrm{NaCl}$ Medium, Arabian J. Sci. Eng., 2018, 1-11, DOI: 10.1007/s13369-018-3160-z.

19 O. Dagdag, A. El Harfi, A. Essamri, M. El Gouri, S. Chraibi, M. Assouag and S. Jodeh, Phosphorous-based epoxy resin composition as an effective anticorrosive coating for steel, Int. J. Ind. Chem., 2018, 1-10, DOI: 10.1007/s40090-0180152-5.

20 S. Fetouaki, A. Elharfi and L. Belkebir, Synthèse d'une nouvelle résine époxyde à base du 2, 2'dihydroxydiphényle, Eur. Polym. J., 2002, 38(4), 787-793.

21 B. Ramezanzadeh, P. Kardar, G. Bahlakeh, Y. Hayatgheib and M. Mahdavian, Fabrication of a highly tunable graphene oxide composite through layer-by-layer assembly of highly crystalline polyaniline nanofibers and green corrosion inhibitors: complementary experimental and first-principles quantum-mechanics modeling approaches, J. Phys. Chem. C, 2017, 121(37), 20433-20450.

22 G. Bahlakeh and B. Ramezanzadeh, A detailed molecular dynamics simulation and experimental investigation on the interfacial bonding mechanism of an epoxy adhesive on carbon steel sheets decorated with a novel ceriumlanthanum nanofilm, ACS Appl. Mater. Interfaces, 2017, 9(20), 17536-17551.

23 G. Bahlakeh, M. Ghaffari, M. R. Saeb, B. Ramezanzadeh, F. De Proft and H. Terryn, A close-up of the effect of iron oxide type on the interfacial interaction between epoxy and carbon steel: combined molecular dynamics simulations and quantum mechanics, J. Phys. Chem. C, 2016, 120(20), 11014-11026.

24 M. Das, A. Biswas, B. K. Kundu, S. M. Mobin, G. Udayabhanu and S. Mukhopadhyay, Targeted synthesis of cadmium (II) Schiff base complexes towards corrosion inhibition on mild steel, RSC Adv., 2017, 7(77), 48569-48585.

25 K. O. Sulaiman, A. T. Onawole, O. Faye and D. T. Shuaib, Understanding the corrosion inhibition of mild steel by selected green compounds using chemical quantum based assessments and molecular dynamics simulations, J. Mol. Liq., 2019, 279, 342-350.

26 N. A. Negm, M. A. Migahed, R. K. Farag, A. A. Fadda, M. K. Awad and M. M. Shaban, High performance corrosion inhibition of novel tricationic surfactants on carbon steel in formation water: Electrochemical and computational evaluations, J. Mol. Liq., 2018, 262, 363-375.

27 S. K. Saha and P. Banerjee, Introduction of newly synthesized Schiff base molecules as efficient corrosion inhibitors for mild steel in $1 \mathrm{M} \mathrm{HCl} \mathrm{medium:} \mathrm{an}$ experimental, density functional theory and molecular dynamics simulation study, Mater. Chem. Front., 2018, 2(9), 1674-1691.

28 B. Mennucci, E. Cances and J. Tomasi, Evaluation of solvent effects in isotropic and anisotropic dielectrics and in ionic 
solutions with a unified integral equation method: theoretical bases, computational implementation, and numerical applications, J. Phys. Chem. B, 1997, 101, 1050610517.

29 D. Sukul, A. Pal, S. K. Saha, S. Satpati, U. Adhikari and P. Banerjee, Newly synthesized quercetin derivatives as corrosion inhibitors for mild steel in $1 \mathrm{M} \mathrm{HCl}$ : combined experimental and theoretical investigation, Phys. Chem. Chem. Phys., 2018, 20(9), 6562-6574.

30 S. Cao, D. Liu, H. Ding, J. Wang, H. Lu and J. Gui, Corrosion inhibition effects of a novel ionic liquid with and without potassium iodide for carbon steel in $0.5 \mathrm{M} \mathrm{HCl}$ solution: An experimental study and theoretical calculation, J. Mol. Liq., 2019, 275, 729-740.

31 R. G. Parr, R. A. Donnelly, M. Levy and W. E. Palke, Electronegativity: the density functional viewpoint, J. Chem. Phys., 1978, 68, 3801-3807.

32 R. G. Parr and R. G. Pearson, Absolute hardness: companion parameter to absolute electronegativity, J. Am. Chem. Soc., 1983, 105, 7512-7516.

33 R. G. Pearson, Absolute electronegativity and hardness: application to inorganic chemistry, Inorg. Chem., 1988, 27, 734-740.

34 P. Geerlings, F. De Proft and W. Langenaeker, Conceptual density functional theory, Chem. Rev., 2003, 103, 1793-1874.

35 R. Roy, S. Krishnamurti, P. Geerlings and S. Pal, Local softness and hardness based reactivity descriptors for predicting intra-and intermolecular reactivity sequences: carbonyl compounds, J. Phys. Chem. A, 1998, 102, 3746-3755.

$36 \mathrm{~S}$. Martinez, Inhibitory mechanism of mimosa tannin using molecular modeling and substitutional adsorption isotherms, Mater. Chem. Phys., 2003, 77, 97-102.

37 A. Dutta, S. K. Saha, P. Banerjee, A. K. Patra and D. Sukul, Evaluating corrosion inhibition property of some Schiff bases for mild steel in $1 \mathrm{M} \mathrm{HCl}$ : competitive effect of the heteroatom and stereochemical conformation of the molecule, $R S C A d v$., 2016, 6, 74833-74844.

38 R. Wu, X. Qiu, Y. Shi and M. Deng, Molecular dynamics simulation of the atomistic monolayer structures of N-acyl amino acid-based surfactants, Mol. Simul., 2017, 43, 491501.

39 V. Sastri and J. Perumareddi, Molecular orbital theoretical studies of some organic corrosion inhibitors, Corrosion, 1997, 53, 617-622.

40 B. Gomez, N. Likhanova, M. Dominguez-Aguilar, R. Martinez-Palou, A. Vela and J. L. Gazquez, Quantum chemical study of the inhibitive properties of 2-pyridylazoles, J. Phys. Chem. B, 2006, 110, 8928-8934.

41 M. Bouanis, M. Tourabi, A. Nyassi, A. Zarrouk, C. Jama and F. Bentiss, Corrosion inhibition performance of 2, 5-bis(4dimethylaminophenyl)-1, 3, 4-oxadiazole for carbon steel in $\mathrm{HCl}$ solution: Gravimetric, electrochemical and XPS studies, Appl. Surf. Sci., 2016, 389, 952-966.

42 K. Fukui, Role of frontier orbitals in chemical reactions, Science, 1982, 218, 747-754.
43 K. Fukui, The role of frontier orbitals in chemical reactions, Frontier Orbitals and Reaction Paths: Selected Papers of Kenichi Fukui, World Scientific, 1997, pp. 150-170.

44 B. Tan, S. Zhang, H. Liu, Y. Guo, Y. Qiang, W. Li and S. Chen, Corrosion inhibition of X65 steel in sulfuric acid by two food flavorants 2-isobutylthiazole and 1-(1, 3-Thiazol-2-yl) ethanone as the green environmental corrosion inhibitors: Combination of experimental and theoretical researches, $J$. Colloid Interface Sci., 2018, 519-529.

45 Y. El Bakri, L. Guo and E. M. Essassi, Electrochemical, DFT and MD simulation of newly synthesized triazolotriazepine derivatives as corrosion inhibitors for carbon steel in $1 \mathbf{M}$ HCl, J. Mol. Liq., 2019, 274, 759-769.

46 S. K. Saha, A. Dutta, P. Ghosh, D. Sukul and P. Banerjee, Novel Schiff-base molecules as efficient corrosion inhibitors for mild steel surface in $1 \mathrm{M} \mathrm{HCl} \mathrm{medium:}$ experimental and theoretical approach, Phys. Chem. Chem. Phys., 2016, 18(27), 17898-17911.

47 Y. El Bakri, L. Guo, A. Harmaoui, A. B. Ali, E. M. Essassi and J. T. Mague, Synthesis, crystal structure, DFT, molecular dynamics simulation and evaluation of the anticorrosion performance of a new pyrazolotriazole derivative, J. Mol. Struct., 2019, 1176, 290-297.

48 S. K. Saha, A. Dutta, P. Ghosh, D. Sukul and P. Banerjee, Adsorption and corrosion inhibition effect of Schiff base molecules on the mild steel surface in $1 \mathrm{M} \mathrm{HCl} \mathrm{medium:}$ a combined experimental and theoretical approach, Phys. Chem. Chem. Phys., 2015, 17(8), 5679-5690.

49 C. Verma, L. O. Olasunkanmi, I. Bahadur, H. Lgaz, M. A. Quraishi, J. Haque and E. E. Ebenso, Experimental, density functional theory and molecular dynamics supported adsorption behavior of environmental benign imidazolium based ionic liquids on mild steel surface in acidic medium, J. Mol. Liq., 2019, 273, 1-15.

50 Z. Sanaei, M. Ramezanzadeh, G. Bahlakeh and B. Ramezanzadeh, Use of Rosa canina fruit extract as a green corrosion inhibitor for mild steel in $1 \mathrm{M} \mathrm{HCl}$ solution: A complementary experimental, molecular dynamics and quantum mechanics investigation, J. Ind. Eng. Chem., 2019, 69, 18-31.

51 N. Asadi, M. Ramezanzadeh, G. Bahlakeh and B. Ramezanzadeh, Utilizing Lemon Balm extract as an effective green corrosion inhibitor for mild steel in $1 \mathrm{M}$ $\mathrm{HCl}$ solution: A detailed experimental, molecular dynamics, Monte Carlo and quantum mechanics study, $J$. Taiwan Inst. Chem. Eng., 2019, 95, 252-272.

52 M. M. Solomon, S. A. Umoren, I. B. Obot, A. A. Sorour and H. Gerengi, Exploration of Dextran for Application as Corrosion Inhibitor for Steel in Strong Acid Environment: Effect of Molecular Weight, Modification, and Temperature on Efficiency, ACS Appl. Mater. Interfaces, 2018, 10(33), 28112-28129.

53 C. Verma, M. A. Quraishi, E. E. Ebenso, I. B. Obot and A. El Assyry, 3-Amino alkylated indoles as corrosion inhibitors for mild steel in $1 \mathrm{M} \mathrm{HCl}$ : Experimental and theoretical studies, J. Mol. Liq., 2016, 219, 647-660. 
54 M. R. Vinutha, T. V. Venkatesha and C. Nagaraja, Anticorrosive ability of electrochemically synthesized 2, 2'disulfanediyldianiline for mild steel corrosion: electrochemical and thermodynamic studies, Int. J. Ind. Chem., 2018, 1-13.

$55 \mathrm{~S}$. B. Aoun, On the corrosion inhibition of carbon steel in $1 \mathrm{M}$ $\mathrm{HCl}$ with a pyridinium-ionic liquid: chemical, thermodynamic, kinetic and electrochemical studies, RSC Adv., 2017, 7(58), 36688-36696.

56 A. Pandey, B. Singh, C. Verma and E. E. Ebenso, Synthesis, characterization and corrosion inhibition potential of two novel Schiff bases on mild steel in acidic medium, RSC Adv., 2017, 7(74), 47148-47163.

57 R. Aslam, M. Mobin, J. Aslam and H. Lgaz, Sugar based N, N'didodecyl-N, $\mathrm{N}^{\prime}$ digluconamideethylenediamine gemini surfactant as corrosion inhibitor for mild steel in $3.5 \%$ $\mathrm{NaCl}$ solution-effect of synergistic KI additive, Sci. Rep., 2018, 8(1), 3690.

58 K. Ramya, R. Mohan and A. Joseph, Interaction of benzimidazoles and benzotriazole: its corrosion protection properties on mild steel in hydrochloric acid, J. Mater. Eng. Perform., 2014, 23(11), 4089-4101.

59 H. M. A. El-Lateef, M. S. S. Adam and M. M. Khalaf, Synthesis of polar unique $3 \mathrm{~d}$ metal-imine complexes of salicylidene anthranilate sodium salt. Homogeneous catalytic and corrosion inhibition performance, J. Taiwan Inst. Chem. Eng., 2018, 88, 286-304.

60 M. Murmu, S. K. Saha, N. C. Murmu and P. Banerjee, Effect of stereochemical conformation into the corrosion inhibitive behaviour of double azomethine based Schiff bases on mild steel surface in $1 \mathrm{~mol} \mathrm{~L}^{-1} \mathrm{HCl}$ medium: An experimental, density functional theory and molecular dynamics simulation study, Corros. Sci., 2019, 146, 134-151.

61 A. Dehghani, G. Bahlakeh and B. Ramezanzadeh, A detailed electrochemical/theoretical exploration of the aqueous Chinese gooseberry fruit shell extract as a green and cheap corrosion inhibitor for mild steel in acidic solution, J. Mol. Liq., 2019, 282, 366-384.

62 R. Haldhar, D. Prasad, A. Saxena and P. Singh, Valeriana wallichii root extract as a green \& sustainable corrosion inhibitor for mild steel in acidic environments: experimental and theoretical study, Mater. Chem. Front., 2018, 2(6), 1225-1237.

63 A. Espinoza-Vázquez, F. J. Rodríguez-Gómez, B. I. VergaraArenas, L. Lomas-Romero, D. Angeles-Beltrán, G. E. Negrón-Silva and J. A. Morales-Serna, Synthesis of 1, 2, 3-triazoles in the presence of mixed $\mathrm{Mg} / \mathrm{Fe}$ oxides and their evaluation as corrosion inhibitors of API 5L X70 steel submerged in $\mathrm{HCl}$, RSC Adv., 2017, 7(40), 24736-24746.

64 M. El Faydy, R. Touir, M. E. Touhami, A. Zarrouk, C. Jama, B. Lakhrissi and F. Bentiss, Corrosion inhibition performance of newly synthesized 5-alkoxymethyl-8hydroxyquinoline derivatives for carbon steel in $1 \mathrm{M} \mathrm{HCl}$ solution: experimental, DFT and Monte Carlo simulation studies, Phys. Chem. Chem. Phys., 2018, 20(30), 20167-20187.

65 T. Douadi, H. Hamani, D. Daoud, M. Al-Noaimi and S. Chafaa, Effect of temperature and hydrodynamic conditions on corrosion inhibition of an azomethine compounds for mild steel in $1 \mathrm{M} \mathrm{HCl}$ solution, J. Taiwan Inst. Chem. Eng., 2017, 71, 388-404.

66 A. Ghazoui, N. Benchat, F. El-Hajjaji, M. Taleb, Z. Rais, R. Saddik and B. Hammouti, The study of the effect of ethyl (6-methyl-3-oxopyridazin-2-yl) acetate on mild steel corrosion in $1 \mathrm{M} \mathrm{HCl}, \mathrm{J}$. Alloys Compd., 2017, 693, 510-517.

67 M. Mobin and M. Rizvi, Polysaccharide from Plantago as a green corrosion inhibitor for carbon steel in $1 \mathrm{M} \mathrm{HCl}$ solution, Carbohydr. Polym., 2017, 160, 172-183.

68 X. Ma, X. Jiang, S. Xia, M. Shan, X. Li, L. Yu and Q. Tang, New corrosion inhibitor acrylamide methyl ether for mild steel in $1 \mathrm{M} \mathrm{HCl}$, Appl. Surf. Sci., 2016, 371, 248-257.

69 M. A. Quraishi, 2-Amino-3, 5-dicarbonitrile-6-thio-pyridines: new and effective corrosion inhibitors for mild steel in $1 \mathrm{M}$ HCl, Ind. Eng. Chem. Res., 2014, 53(8), 2851-2859.

70 M. A. Deyab, R. Ouarsal, M. Lachkar, B. El Bali and R. Essehli, Phosphites compound: Novel corrosion inhibitor for radioactive waste container (carbon steel) in simulated Callovo-Oxfordian (COx) groundwater, J. Mol. Liq. , 2016, 219, 994-999.

71 R. Hsissou, S. Abbout, A. Berisha, M. Berradi, M. Assouag, N. Hajjaji and A. Elharfi, Experimental, DFT and molecular dynamics simulation on the inhibition performance of the DGDCBA epoxy polymer against the corrosion of the E24 carbon steel in $1.0 \mathrm{M} \mathrm{HCl}$ solution, J. Mol. Struct., 2019, 1182, 340-351.

72 N. El-Aouni, A. Benabida, M. Cherkaoui and A. Elharfi, A new epoxy resin based organic molecule as an effective inhibitor of mild steel corrosion in a sulfuric acid medium, J. Chem. Technol. Metall., 2018, 53(5), 878-890.

73 M. Mihit, K. Laarej, H. A. El Makarim, L. Bazzi, R. Salghi and B. Hammouti, Study of the inhibition of the corrosion of copper and zinc in $\mathrm{HNO}_{3}$ solution by electrochemical technique and quantum chemical calculations, Arabian $J$. Chem., 2010, 3(1), 55-60.

74 S. K. Saha, P. Ghosh, A. Hens, N. C. Murmu and P. Banerjee, Density functional theory and molecular dynamics simulation study on corrosion inhibition performance of mild steel by mercapto-quinoline Schiff base corrosion inhibitor, Phys. E, 2015, 66, 332-341.

75 Ș. Erdoğan, Z. S. Safi, S. Kaya, D. Ö. Ișın, L. Guo and C. Kaya, A computational study on corrosion inhibition performances of novel quinoline derivatives against the corrosion of iron, J. Mol. Struct., 2017, 1134, 751-761.

76 L. Guo, Z. S. Safi, S. Kaya, W. Shi, B. Tüzün, N. Altunay and C. Kaya, Anticorrosive Effects of Some Thiophene Derivatives Against the Corrosion of Iron: A Computational Study, Front. Chem., 2018, 6, 155.

77 S. Xia, M. Qiu, L. Yu, F. Liu and H. Zhao, Molecular dynamics and density functional theory study on relationship between structure of imidazoline derivatives and inhibition performance, Corros. Sci., 2008, 50(7), 2021-2029.

78 B. Hammouti, A. Dafali, R. Touzani and M. Bouachrine, Inhibition of copper corrosion by bipyrazole compound in aerated 3\% NaCl, J. Saudi Chem. Soc., 2012, 16(4), 413-418. 
79 F. Zhang, Y. Tang, Z. Cao, W. Jing, Z. Wu and Y. Chen, Performance and theoretical study on corrosion inhibition of 2-(4-pyridyl)-benzimidazole for mild steel in hydrochloric acid, Corros. Sci., 2012, 61, 1-9.

80 M. Yadav, R. R. Sinha, S. Kumar, I. Bahadur and E. E. Ebenso, Synthesis and application of new acetohydrazide derivatives as a corrosion inhibition of mild steel in acidic medium: Insight from electrochemical and theoretical studies, J. Mol. Liq., 2015, 208, 322-332.

81 N. Kovačević and A. Kokalj, Analysis of molecular electronic structure of imidazole-and benzimidazole-based inhibitors: a simple recipe for qualitative estimation of chemical hardness, Corros. Sci., 2011, 53(3), 909-921.

$82 \mathrm{~A}$. Kokalj, Is the analysis of molecular electronic structure of corrosion inhibitors sufficient to predict the trend of their inhibition performance, Electrochim. Acta, 2010, 56(2), 745755.

83 N. A. Wazzan and F. M. Mahgoub, DFT calculations for corrosion inhibition of ferrous alloys by pyrazolopyrimidine derivatives, Open J. Phys. Chem., 2014, $4(01), 6$.

84 V. S. Sastri and J. R. Perumareddi, Molecular orbital theoretical studies of some organic corrosion inhibitors, Corrosion, 1997, 53(8), 617-622.
85 B. Gomez, N. V. Likhanova, M. A. Dominguez-Aguilar, R. Martinez-Palou, A. Vela and J. L. Gazquez, Quantum chemical study of the inhibitive properties of 2-pyridylazoles, J. Phys. Chem. B, 2006, 110(18), 8928-8934.

86 X. Li, S. Deng, H. Fu and T. Li, Adsorption and inhibition effect of 6-benzylaminopurine on cold rolled steel in $1.0 \mathrm{M}$ HCl, Electrochim. Acta, 2009, 54(16), 4089-4098.

87 Z. S. Safi and S. Omar, Proton affinity and molecular basicity of m-and p-substituted benzamides in gas phase and in solution: a theoretical study, Chem. Phys. Lett., 2014, 610, 321-330.

88 L. Guo, I. B. Obot, X. Zheng, X. Shen, Y. Qiang, S. Kaya and C. Kaya, Theoretical insight into an empirical rule about organic corrosion inhibitors containing nitrogen, oxygen, and sulfur atoms, Appl. Surf. Sci., 2017, 406, 301-306.

89 S. Deng, X. Li and X. Xie, Hydroxymethyl urea and 1, 3bis(hydroxymethyl) urea as corrosion inhibitors for steel in HCl solution, Corros. Sci., 2014, 80, 276-289.

$90 \mathrm{~S}$. Deng, X. Li and $\mathrm{H}$. Fu, Two pyrazine derivatives as inhibitors of the cold rolled steel corrosion in hydrochloric acid solution, Corros. Sci., 2011, 53(2), 822-828. 